\author{
Federal Reserve Bank of Dallas \\ Globalization and Monetary Policy Institute \\ Working Paper No. 289 \\ http://www.dallasfed.org/assets/documents/institute/wpapers/2016/0289.pdf
}

\title{
Globalization, Market Structure and Inflation Dynamics *
}

\author{
Sophie Guilloux-Nefussi \\ Banque de France
}

November 3, 2016

\begin{abstract}
The decline in the sensitivity of inflation to domestic slack observed in developed countries since the mid 1980's has been often attributed to globalization. However, this intuition has so far not been formalized. I develop a general equilibrium setup in which the sensitivity of inflation to marginal cost decreases when international trade costs fall. In order to do so, I add three ingredients to an otherwise standard two-country new-Keynesian model. Strategic interactions generate a time varying desired markup; endogenous entry and heterogeneous productivity engender a self-selection of the most productive firms (also the largest ones) in international trade. Hence the weight of large firms in domestic production increases. These firms transmit less marginal cost fluctuations to price adjustments, rather absorbing them into their desired markup in order to protect their market share. At the aggregate level, domestic inflation reacts less to real activity fluctuations.
\end{abstract}

JEL codes: E31, F41, F62

\footnotetext{
* Sophie Guilloux-Nefussi, Banque de France, Monetary and Financial Research Department - Monetary Policy Research Unit, 31 rue Croix de Petits Champs, 75001 Paris, France. sophie.nefussi@gmail.com. I have particularly benefited from detailed discussions and comments by Thomas Chaney, Behzad Diba, Pedro Gete, Jean Imbs, Oleg Itskhoki, Philippe Martin, Isabelle Méjean, and Harald Uhlig. I thank as well Philippe Andrade, Pamfili Antipa, Jean Barthélemy, Vincent Bignon, Luca Guerrieri, Christian Hellwig, Julien Matheron, Eric Mengus, Adrian Penalver, Lionel Potier and Andrea Tambalotti for their thoughtful remarks and feedback. All remaining errors are mine. I am also grateful to seminar participants at the 2014 ADRES doctoral Conference in Economics, the 2014 International Symposium on Money, Banking and Finance, the 2014 European Economic Association Congress, the 2015 Theories and Methods in Macroeconomics (T2M) Conference, the 2015 Dynamics, Economic Growth, and International Trade Conference, the 2015 Midwest Macro Meetings, the 2015 Bank of England/Banque de France International MacroWorkshop, the 2016 Sciences-Po/Banque de France workshop on Granularity, and the 2016 NBER Summer Institute ITM. The views in this paper are those of the author and do not necessarily reflect the views of the Banque de France, the Federal Reserve Bank of Dallas or the Federal Reserve System.
} 


\title{
Globalization, Market Structure and Inflation Dynamics
}

\author{
Sophie Guilloux-Nefussi*
}

November 3, 2016

\footnotetext{
*Banque de France - Monetary and Financial Research Department - Monetary Policy Research Unit, 31 rue Croix de Petits Champs, 75001 Paris, France. e-mail: sophie.nefussi@gmail.com. The views expressed in this paper do not necessarily reflect the opinion of the Banque de France. I have particularly benefited from detailed discussions and comments by Thomas Chaney, Behzad Diba, Pedro Gete, Jean Imbs, Oleg Itskhoki, Philippe Martin, Isabelle Méjean, and Harald Uhlig. I thank as well Philippe Andrade, Pamfili Antipa, Jean Barthélemy, Vincent Bignon, Luca Guerrieri, Christian Hellwig, Julien Matheron, Eric Mengus, Adrian Penalver, Lionel Potier and Andrea Tambalotti for their thoughtful remarks and feedback. All remaining errors are mine. I am also grateful to seminar participants at the 2014 ADRES doctoral Conference in Economics, the 2014 International Symposium on Money, Banking and Finance, the 2014 European Economic Association Congress, the 2015 Theories and Methods in Macroeconomics (T2M) Conference, the 2015 Dynamics, Economic Growth, and International Trade Conference, the 2015 Midwest Macro Meetings, the 2015 Bank of England/Banque de France International Macro Workshop, the 2016 Sciences-Po/Banque de France workshop on Granularity, and the 2016 NBER Summer Institute ITM.
} 


\begin{abstract}
The decline in the sensitivity of inflation to domestic slack observed in developed countries since the mid 1980's has been often attributed to globalization. However, this intuition has so far not been formalized. I develop a general equilibrium setup in which the sensitivity of inflation to marginal cost decreases when international trade costs fall. In order to do so, I add three ingredients to an otherwise standard two-country new-Keynesian model. Strategic interactions generate a time varying desired markup; endogenous entry and heterogeneous productivity engender a self-selection of the most productive firms (also the largest ones) in international trade. Hence the weight of large firms in domestic production increases. These firms transmit less marginal cost fluctuations to price adjustments, rather absorbing them into their desired markup in order to protect their market share. At the aggregate level, domestic inflation reacts less to real activity fluctuations.
\end{abstract}

Keywords: Inflation; Impact of Globalization; Strategic Interactions; Market Structure; Phillips Curve. JEL Classification Numbers: E31,F41,F62. 


\section{Introduction}

In spite of the dramatic economic contraction following the Lehman collapse and the ensuing subdued growth dynamics, inflation has displayed remarkable stability. This "missing disinflation"puzzle has drawn renewed attention on the fundamental forces behind the loosening of the inflation-output tradeoff observed in advanced countries since the mid 1980's. ${ }^{1}$

Improvement in monetary policy making -towards enhanced central bank independence and inflation targeting- has certainly helped anchor inflation expectations and contributed to the growing stability of inflation over the last thirty years. Recent empirical studies have also pointed to another more structural change: controlling for inflation expectations, the magnitude of the increase in inflation resulting from a given expansion of domestic demand has become significantly lower today than it was in the early 1980's. ${ }^{2}$ Among the possible explanations for that structural transformation, globalization has stood as one of the prime suspects. Intuitively, as openness to international trade increases, some producers adjust their pricing behavior for fear of losing their market share. This should in principle affect how inflation responds to the slack/tightness of the domestic economy. Yet, despite its appeal, it has proven extremely difficult to formalize this simple story.

In this paper, I provide a novel analytical framework that can replicate the declining sensitivity of domestic inflation to real activity in response to globalization. I include three ingredients into an otherwise standard two-country new-Keynesian model: strategic interactions -due to oligopolistic competition-, endogenous entry on the export market -due to fixed penetration costs- and heterogeneity in firms' productivity. I define globalization as a fall in international per-unit trade costs. The set of competitors endogenously changes as it becomes profitable for new firms to export (Endogenous Entry assumption). By the Productivity Heterogeneity assumption, only the most productive

\footnotetext{
${ }^{1}$ A non-exhaustive list of publications on that question includes Kohn (2006), Bernanke (2007), or, more recently, Ball and Mazumder (2011), Peach et al. (2011), Gordon (2013), International Monetary Fund (2013), Fratto and Uhlig (2014), Coibion and Gorodnichenko (2015), Blanchard et al. (2015). In a different approach, Gopinath et al. (2012) also study the dynamic properties of prices over the business cycle, but they focus specifically on trade prices during the trade collapse -from August 2008 to March 2009. They show that the sharp drop in differentiated goods trade came about entirely through quantities, while prices remained pretty stable.

${ }^{2}$ In a new-Keynesian perspective, this is referred to as the flattening of the Phillips curve. See Borio and Filardo (2007), Ball and Mazumder (2011), International Monetary Fund (2013), and Blanchard et al. (2015) for empirical evidence. Sbordone (2010)'s introduction also provides a detailed review of the literature documenting such a structural change.
} 
firms choose to export, which also happen to be the largest firms. ${ }^{3}$ Because of the Strategic Interactions assumption, largest firms are the ones most prone to act strategically by absorbing marginal cost movements into their markup in order to protect their market share. Thus, they transmit less marginal cost fluctuations into price adjustments, compared to smaller firms.

Eventually, openness to international trade gives rise to two forces: (i) pro-competitive pressures, as foreign competitors penetrate the domestic market, and (ii) greater concentration, as the weight of large firms in domestic production increases. If the concentration force dominates, then globalization strengthens the overall degree of real rigidities, ${ }^{4}$ which translates into inflation responding less to domestic slack.

I further demonstrate why each assumption is necessary, but not sufficient in itself, to produce the weakening of the relationship between inflation and domestic slack in response to globalization. To establish this point, the mechanics can be decomposed into two parts: (1) How does the elasticity of inflation to marginal cost vary with the market structure? (2) How does the market structure, i.e. the number of firms and their relative market power, change with globalization?

How does the elasticity of inflation to domestic slack vary with the market structure? The view that the level of competition might affect the responsiveness of inflation to domestic fluctuations presumes that firms act strategically, by adjusting their markup in response to the perceived competition.

In order to capture the strategic interactions channel, I relax the standard fixed price elasticity of demand assumption. To that end, I introduce oligopolistic competition at the sector level, stating that firms compete in quantities, à la Cournot, within sectors. ${ }^{5}$ Firms internalize their influence on the sectoral output when setting their optimal plans. As a result, the perceived price-elasticity of demand, and subsequently the desired markup, ${ }^{6}$ vary with firm's market share. ${ }^{7}$ As in Amiti et al.

\footnotetext{
${ }^{3}$ This result is in line with standard heterogenous-firm trade models à la Melitz (2003) or Chaney (2008) where the most productive firm sets the lowest relative price and hence captures the largest market share.

${ }^{4}$ Defined after Ball and Romer (1990) as forces that reduce the responsiveness of firms optimal prices to variations in aggregate output resulting from variations in real aggregate demand.

${ }^{5}$ In the vein of Dornbusch (1987), Krugman (1987), Atkeson and Burstein (2008), Benigno and Faia (2010), or Amiti et al. (2015).

${ }^{6}$ The one prevailing under flexible prices.

${ }^{7}$ There exists alternative ways to account for time varying markups. Instead of supply side strategic complementarities, Melitz and Ottaviano (2008), Sbordone (2010) or Guerrieri et al. (2010) rely on demand side complementarities, introducing demand functions that directly relates the elasticity of substitution between goods to the number of available goods. Differently, Berman et al. (2012) assume distribution costs in order to generate variable producer markups.
} 
(2015), large firms (with high market power) exhibit greater strategic complementarities compared to small firms. They have more elastic markups and lower pass-through of the cost shocks.

Coupled with nominal rigidities, the degree of firms' market power determines the strength of the relationship between inflation and domestic slack. As in Woodford (2003), for a given degree of nominal rigidities, the stronger the strategic interactions (also referred to as real rigidities), the weaker the relationship between inflation and real marginal cost. Intuitively, large firms respond to a marginal cost shock by absorbing part of that shock into their desired markup, which mechanically reduces the pass-through of real marginal cost into inflation. Thus, if an economy is populated by a few large firms (in each sector), the buffer-effect stemming from strategic markup adjustments is very pronounced. On the contrary, if firms' market share becomes infinitely small, strategic interactions vanish. Knowing that the link between domestic inflation and real activity loosens when firms have more market power, the remaining question regards the impact of globalization on firms' market share/market power.

How does the market structure change with globalization? The answer depends on how globalization is identified. Sbordone (2010) and Benigno and Faia (2010) consider symmetric firms and model globalization as an increase in the overall number of varieties (or equivalently firms), $N$. More competitors entail a decline in each firm's market share $(\xi=1 / N)$. Such a definition of globalization leads to a decline in firms' market power and consequently reduces the scope for strategic markup adjustments. Thus inflation reacts more strongly to marginal cost movements. This effect is the purely pro-competitive impact of globalization.

Differently from the previous papers, I borrow from the new trade literature and I argue that globalization might favor concentration through the emergence of "big players". In the spirit of Melitz (2003) and Chaney (2008), I rely on two assumptions: the set of exporters is endogenous, due to fixed penetration costs on the export market; and firms are heterogeneous in productivity. When the iceberg trade cost falls, only the high-productivity firms choose to export and high-productivity firms are also large ones as in Atkeson and Burstein (2008) or Berman et al. (2012). Therefore new firms who enter the export market have more market power than the average. They are consequently relatively more prone to act strategically, by adjusting their desired markup. Hence, in the presence of nominal rigidities in the short run, their price adjustments respond less to cyclical flucIn all cases, the result is that large firms would less pass-through aggregate shocks into prices (relative to small firms). 
tuations in real marginal cost. At the aggregate level, the proportion of "large market share" firms producing domestic output increases with globalization. As a result, domestic inflation becomes less responsive to domestic slack. In a new-Keynesian setup, this means that the Phillips curve flattens.

The mechanism that I highlight suggests that, in the long run, economies have become more concentrated. This re-allocation / concentration channel $^{8}$ strengthens the overall degree of real rigidities in the economy and can counterbalance the pro-competitive force.

This result is in fact in line with empirical findings. Decomposing the reasoning into three steps, I show that each of them is supported by well-established micro evidence. (1) Large firms have higher and more elastic markups and, as a result, do less pass-through cost shocks into prices (Berman et al. (2012), Amiti et al. (2015)). (2) The share of output produced by large firms increases with globalization due to the self-selection of exporters (Bernard et al. (2007), Eaton et al. (2011)). (3) Consequently, the aggregate market power -weighted by firms share in domestic output- increases with globalization. This last point is consistent with De Loecker et al. (2016) findings, even though it comes from a different channel. They show that the firm-level markup can increase after a trade liberalization as firms take advantage of cheaper imported inputs to increase their markups. This channel is absent from my setup, but I show that the aggregate markup in the economy can increase due to a reallocation of production towards large firms.

The rest of the paper proceeds as follows. Section 1 reviews the related literature. Section 2 describes the model. Section 3 derives the new-Keynesian Phillips curve (aggregating heterogeneous firms' behaviors) that relates domestic inflation to marginal cost. Section 4 provides a numerical example. Section 5 reviews empirical support for an increase in the overall degree of firms' market power since the eighties.

\section{Related literature}

My contribution connects different strands of the literature.

First, this paper shares ingredients with the international trade literature on pricing-to-market and imperfect exchange rate pass-through. The survey by Burstein and Gopinath (2013) points out that strategic interactions are sufficient to generate pricing-to-market and imperfect pass-through,

\footnotetext{
${ }^{8}$ In the sense that domestic production is re-allocated towards larger firms.
} 
even absent of any nominal rigidities. This result still holds in my model. In the long run, when prices are flexible, the model boils down to Atkeson and Burstein (2008)'s framework. My results are also consistent with other models where the heterogeneity in pass-through is driven by firm specific productivity, as in Berman et al. (2012) for instance.

However, my approach differs from the international trade literature on imperfect pass-through as I consider a sticky price environment. I am focusing on how the combination of strategic interactions and nominal rigidities in the short run affects the inflation/real marginal cost nexus. As opposed to Atkeson and Burstein (2008) or Amiti et al. (2015), I do not focus on the link between prices and nominal marginal costs, but I am looking at the relationship between inflation and the level of the real marginal cost (as a proxy for domestic slack). Yet, the similarity stems from the underlying force (the role of large firms) that can both generate a decline in exchange rate passthrough in the long run and, as a corollary, make inflation respond less to marginal cost shocks in the short run.

Second, this paper is related to the new-Keynesian open economy literature. Standard newKeynesian open-economy models à la Gali and Monacelli (2008) show how import prices have a direct effect on consumer price inflation proportionally to their share in the consumption basket. Besides, domestic producer price inflation is related to the terms of trade insofar as the latter influences the domestic real marginal cost.

I consider another channel that works through firms' strategic behavior and directly affects the slope of the Phillips curve. In that sense, my work is very close to Sbordone (2010) ${ }^{9}$, Benigno and Faia (2010) and Guerrieri et al. (2010) who embed strategic interactions into otherwise standard DSGE models in order to assess the impact of globalization on inflation dynamics. However, it differs in a crucial aspect: instead of defining globalization as an increase in the number of goods, I define globalization as a fall in trade costs that allows for both (i) the entry of new varieties and (ii) for the selection of the most productive firms (a mechanism for which the international trade literature provides solid evidence).

Third, this work is related to the recent literature embedding endogenous varieties in a newKeynesian setup.

A closely related series of papers deals with optimal monetary policy under endogenous entry:

\footnotetext{
${ }^{9}$ Sbordone studies a closed economy, but the impact of the rest of the world is captured through the number of varieties available to domestic customers.
} 
Bilbiie et al. (2012), Bilbiie et al. (2014), and Bergin and Corsetti (2013) study economies with endogenous firm entry and sluggish price adjustment to derive the optimal monetary policy. Part of this literature also introduces strategic complementarities. In particular, Cecioni (2010), Etro and Colciago (2010), Faia (2012), Lewis and Poilly (2012), or Etro and Rossi (2015) rely on the oligopolistic competition and endogenous firm entry assumptions in a closed economy framework. They find that short-run markups vary countercyclically because, after a positive productivity shock, the entry of new firms reduces the average market share. This stream of the literature concludes that a cyclical increase in the number of operating firms lowers CPI-inflation in the short run. My work differs from those papers along three dimensions: first, I study an open economy; second, I suppose that firms are heterogeneous in productivity. As a result, my model predicts a weaker link between inflation and real activity in response to globalization if the concentration force dominates the pro-competitive one. Third, the focus is different since my goal is to understand the long-run impact of the changes in the market structure while they rather look at the short-run impact of entry/exit of varieties.

Fourth, this work is linked to the literature on granularity in the vein of Gabaix (2011).

The granular hypothesis typically states that a few big firms matter for understanding the macro variables dynamics. My work is very consistent with Di Giovanni and Levchenko (2012) findings: openness to international trade renders economies more granular. The reason is that big firms are favored and their weight in the domestic output increases. Yet, I differ from the aforementioned papers insofar as (i) I am focusing on inflation dynamics in a sticky price environment, whereas they are studying real variables in a flexible price world; and (ii) I consider heterogeneous firms' behavior in response to a common aggregate shock, while they look at idiosyncratic shocks. Nevertheless, the fundamental intuition is very similar. A few big players account for a large part of aggregate movements. Besides, as far as the pricing behavior is concerned, large firms do behave differently from small firms because they have room for playing strategically with their markup.

Fifth, in terms of modeling, this work is closely related to Ghironi and Melitz (2005) and Atkeson and Burstein (2008) insofar as I consider a dynamic two-country economy with an endogenous set of exporters driven by trade costs. The key difference is that I am focusing on a sticky-price environment while they both deal with flexible prices. I simplify Atkeson and Burstein (2008) framework by imposing symmetry across sectors. Assuming the same distribution of productivity across sectors renders the model tractable enough to derive an analytical Phillips curve equation. 
In steady state, there exists an endogenous cutoff productivity value that determines the set of exporters, their prices and the quantities sold. Eventually the steady state market share of firms pins down their market power and incidentally determines how much inflation responds to real marginal cost in the short run.

\section{The Model}

I build on a very standard two-country new-Keynesian general equilibrium model with nominal rigidities à la Rotemberg (1982). My object of interest is the partial equilibrium Phillips curve equation that relates inflation to real marginal cost and inflation expectations. ${ }^{10}$ In such a framework, the response of inflation to real marginal cost (i.e. the slope of the Phillips curve) is pinned down by the steady state market power of firms (inversely related to the price elasticity of demand). The goal of this paper is to compare the slope of the structural Phillips curve in a pre-globalization steady state -characterized by high international trade costs-, versus a post-globalization steady state -low trade costs. To that end, this section starts from the standard new-Keynesian model and gradually amends the supply side in order to allow for endogenous changes in firms' market power.

Note that in the long run, prices are stable and there is no link between real activity and inflation. The slope of the Phillips curve only makes sense in the short run -when stochastic disturbances kick in and nominal frictions matter. Yet, the short-run dynamics of inflation is determined by the long-run (steady state) market structure of the economy (how many producers, what their respective market power is). Hence, the exercise I am carrying out is in effect a comparative static analysis between two steady states characterized by high versus low trade costs.

\subsection{Supply side: basic elements}

To begin with, I describe the standard version of the supply side, from which I will progressively deviate in the next subsections. Assume that the economy is composed of two countries, domestic

\footnotetext{
${ }^{10}$ Admittedly this new-Keynesian structural Phillips curve is only one part of the overall "aggregate Phillips curve" relating inflation to output gap. As emphasized by Sbordone (2010), this link is the most likely to be affected by globalization.
} 
$(D)$ and foreign $(F)$. Suppose for now on that each country is a closed economy (say there exists fixed costs for exporting that are infinitely high). I focus on country $D$, but everything holds symmetrically in $F$ (variables are denoted with a superscript star). The final consumption good is the aggregation of differentiated goods that are imperfect substitutes. Each variety $i$ is produced by a different firm with a constant return to scale production function. Labor is the only input: $x_{t}(i)=A_{t} z_{i} h_{t}(i)$, where $x_{t}(i)$ is the quantity produced and $h_{t}(i)$ is the amount of work. $A_{t}$ is the aggregate productivity in the domestic country, while $z_{i}$ is the firm $i$ relative productivity factor. For expositional simplicity, I first suppose that all firms are identical and I normalize $z_{i}$ to one. I will introduce heterogeneity later on and show the consecutive changes.

When choosing at time $t$ the price $P_{t}^{x}(i)$ that maximizes its expected intertemporal discounted profit, a firm $i$ incurs a price adjustment cost, expressed in units of final consumption, $P A C_{t}(i)=$ $\frac{\phi_{p}}{2}\left[\frac{P_{t}^{x}(i)}{P_{t-1}^{x}(i)}-1\right]^{2} \frac{P_{t}^{x}(i)}{P_{t}} x_{t}(i)$. This cost can be interpreted as the amount of material that a firm must purchase in order to change a price. If the price adjustment cost coefficient, $\phi_{p}$, is zero, the model yields back flexible prices.

In this very standard framework with price sluggishness à la Rotemberg (1982), the optimal price chosen by a firm is a markup over marginal cost. Typically, in a monopolistic competition environment where the final consumption goods is the Dixit-Stiglitz aggregation of symmetric varieties with elasticity of substitution $\theta$, then the desired markup ${ }^{11}$ is constant $\left(\frac{\theta}{\theta-1}\right)$, and the $a c$ tual markup fluctuates because prices adjust only sluggishly to economic conditions. Loglinearizing the actual markup around the steady state gives the new-Keynesian Phillips curve equation: $\pi_{t}=\frac{\theta-1}{\phi_{p}} \hat{m} c_{t}+\beta \mathbb{E} \pi_{t+1}$, where $\pi_{t}=\Pi_{t}-1=\frac{P_{t}}{P_{t-1}}-1$ and $m c_{t}$ denotes the real marginal cost, $m c_{t}=\frac{W_{t}}{A_{t} P_{t}}$. Throughout the paper, the symbol hat denotes the log-deviation of a variable to the steady state. $^{12}$

The goal of this paper is to shed light on how globalization might affect the response of inflation to real marginal cost. I argue that this change might stem from globalization altering the degree of real rigidities in the economy -keeping the degree of nominal rigidities, $\phi_{p}$, constant. To prove that claim, the baseline model ${ }^{13}$ needs to be amended. Precisely, I make firms' behavior depart from the

\footnotetext{
${ }^{11}$ i.e. the one that would prevail absent nominal frictions.

${ }^{12}$ Assuming gross inflation is one in steady state, I write the log-deviation of inflation as $\widehat{\Pi}_{t}=\pi_{t}$.

${ }^{13}$ In which the responsiveness of inflation to real marginal cost, $\frac{\theta-1}{\phi_{p}}$, is purely fixed and exogenous.
} 
standard setup along three dimensions. Oligopolistic competition (assumption A1) replaces the standard monopolistic competition assumption, which entails strategic interactions between firms, rendering firms' market power endogenous. Besides, firms are heterogenous in productivity $(A 2)$ and the set of exporters is endogenous (A3), due to the existence of (finite) fixed costs for exporting. Those last two assumptions engender a self-selection of most productive firms on the export market.

\subsection{Assumption A1: Strategic Interactions among Firms Stemming from Oligopolistic Competition}

In introducing oligopolistic competition, I follow a literature initiated by Dornbusch (1987) and Krugman (1987) or Rotemberg and Woodford (1989), and more recently developed by Atkeson and Burstein (2008) in a flexible price environment or Benigno and Faia (2010) in a sticky price setup. ${ }^{14}$ The idea is that the final consumption good is still the Dixit-Stiglitz aggregation of imperfect substitutable goods, but, differently from the standard case, there are two layers of production:

1. The final consumption good, denoted $Y_{t}$, is composed of differentiated sectoral goods supplied by a continuum of sectors (indexed by $k$ ) on $[0,1]: Y_{t}=\left[\int_{0}^{1} Y_{t}(k)^{\frac{\sigma-1}{\sigma}} d k\right]^{\frac{\sigma}{\sigma-1}}$, where $\sigma$ is the elasticity of substitution between goods from different sectors. The demand for sectoral good is $Y_{t}(k)=\left(\frac{P_{t}(k)}{P_{t}}\right)^{-\sigma} Y_{t}$, where $P_{t}$ is the consumption price index defined as $P_{t}=\left[\int_{0}^{1} P_{t}(k)^{1-\sigma} d k\right]^{\frac{1}{1-\sigma}}$ and $P_{t}(k)$ is the sectoral price.

2. In each sector $k$, the sectoral good is produced by a retailer firm that combines all intermediate goods in $\Omega_{t}^{k}$ to supply $Y_{t}(k)=\left[\sum_{i \in \Omega_{t}^{k}} x_{t}(i)^{\frac{\theta-1}{\theta}}\right]^{\frac{\theta}{\theta-1}}$. The elasticity of substitution between goods within a sector $(\theta)$ is greater than the elasticity of substitution across sectors $(\sigma)$, consistently with Broda and Weinstein (2006) findings. $\Omega_{t}^{k}$ is a countable and finite set.

The final good producer in sector $k$ chooses its optimal production plan to maximize its profit, which gives the demand for good $i: x_{t}(i)=\left(\frac{P_{t}^{x}(i)}{P_{t}(k)}\right)^{-\theta} Y_{t}(k)=\left(\frac{P_{t}^{x}(i)}{P_{t}(k)}\right)^{-\theta}\left(\frac{P_{t}(k)}{P_{t}}\right)^{-\sigma} Y_{t}$, where

\footnotetext{
${ }^{14}$ See also, in a flexible price framework, Amiti et al. (2015), or Auer and Schoenle (2015). Those papers rely on the oligopolistic competition assumption to analyse the imperfect exchange rate pass-though. Closer to my work, a recent strand of the new-Keynesian literature is embedding the oligopolistic competition assumption in a standard Dynamic Stochastic General Equilibrium framework with nominal rigidities: Cecioni (2010), Etro and Colciago (2010), Faia (2012), Lewis and Poilly (2012), or Etro and Rossi (2015).
} 
$P_{t}(k)=\left[\sum_{i \in \Omega_{t}^{k}} P_{t}^{x}(i)^{1-\theta}\right]^{\frac{1}{1-\theta}}$ and $P_{t}^{x}(i)$ is the price of the intermediate good $i$, belonging to sector $k$, at time $t$.

\subsubsection{Strategic Interactions and Time Varying Desired Markup}

$N_{t}^{k}$ is the measure of $\Omega_{t}^{k}$ and represents the number of differentiated goods sold in sector $k$ for producing $Y_{t}(k)$. Since firms are not atomistic within a sector, they take into account their impact on sectoral outcome. I assume that producers compete strategically in quantities, à la Cournot, internalizing their impact on the sectoral output when choosing their optimal quantities plan. Consequently, the perceived elasticity of demand to a firm's own price, $\Theta_{t}(i)$, is not constant, although the elasticity of substitution between goods in sector $k$ is constant $(\theta)$.

$$
\Theta_{t}(i)=-\frac{\partial x_{t}(i)}{\partial P_{t}^{x}(i)} \frac{P_{t}^{x}(i)}{x_{t}(i)}=\left[\frac{1}{\theta}+\left(\frac{1}{\sigma}-\frac{1}{\theta}\right)\left(\frac{\partial P_{t}(k)}{\partial P_{t}^{x}(i)} \frac{P_{t}^{x}(i)}{P_{t}(k)}\right)\right]^{-1}
$$

where $\frac{\partial P_{t}(k)}{\partial P_{t}^{x}(i)} \frac{P_{t}^{x}(i)}{P_{t}(k)}=\frac{P_{t}^{x}(i) x_{t}(i)}{P_{t}(k) Y_{t}(k)}=\left[\frac{P_{t}^{x}(i)}{P_{t}(k)}\right]^{1-\theta}=\xi_{t}(i)$, the market share of good $i$ in sector $k^{15}$ The profit maximization program of firm $i$ at time $t$ is:

$$
\begin{aligned}
& \max _{x_{t+j}(i)} \sum_{j=0}^{\infty} \mathbb{E}_{t}\left[Q_{t, t+j}\left(P_{t+j}^{x}(i) x_{t+j}(i)-\frac{W_{t+j}}{A_{t+j} z_{i}} x_{t+j}(i)-\frac{\phi_{p}}{2}\left(\frac{P_{t+j}^{x}(i)}{P_{t+j-1}^{x}(i)}-1\right)^{2} P_{t+j}^{x}(i) x_{t+j}(i)\right)\right] \\
& \text { s.t. } P_{t}^{x}(i)=\left(\frac{x_{t}(i)}{Y_{t}(k)}\right)^{-\frac{1}{\theta}} P_{t}(k)
\end{aligned}
$$

where $Q_{t, t+j}$ is a stochastic discount factor defined in Appendix C.

The first order condition implies that the optimal price is a markup over marginal cost:

$$
P_{t}^{x}(i)=\mu_{t}^{x}(i) \frac{W_{t}}{A_{t} z_{i}}
$$

\footnotetext{
${ }^{15}$ Note that there is a slight abuse of notation here since I should in principle explicitly write that $i$ belongs to sector $k$. I try to alleviate the notation, but the reader should keep in mind that the market share, $\xi_{t}(i)$, is defined at the sector level. In the rest of the paper I will use the symmetry across sectors and will be allowed to drop the notation $k$ anyway.
} 
where:

$$
\begin{aligned}
& \mu_{t}(i)=\frac{\Theta_{t}(i)}{\left(\Theta_{t}(i)-1\right)\left[1-\frac{\phi_{p}}{2}\left(\Pi_{t}^{x}(i)-1\right)^{2}\right]+\phi_{p} \Pi_{t}^{x}(i)\left(\Pi_{t}^{x}(i)-1\right)-\Gamma_{t}(i)} \\
& \Theta_{t}(i)=\left[\frac{1}{\theta}+\left(\frac{1}{\sigma}-\frac{1}{\theta}\right)\left[\frac{P_{t}^{x}(i)}{P_{t}(k)}\right]^{1-\theta}\right]^{-1} \\
& \Gamma_{t}(i)=\phi_{p} \mathbb{E}\left[Q_{t, t+1} \Pi_{t+1}^{x}(i)^{2}\left(\Pi_{t+1}^{x}(i)-1\right) \frac{x_{t+1}(i)}{x_{t}(i)}\right] \\
& \Pi_{t}^{x}(i)=\frac{P_{t}^{x}(i)}{P_{t-1}^{x}(i)}
\end{aligned}
$$

Under flexible prices, the markup becomes $\mu_{t}^{\text {desired }}(i)=\frac{\Theta_{t}(i)}{\Theta_{t}(i)-1}$. Unlike monopolistic competition, the desired markup is not constant over time but depends on the firm's price elasticity of demand $\left(\Theta_{t}(i)\right)$ that is negatively related to its market share through equation $1 .{ }^{16}$ The standard monopolistic case is nested into the model for specific parameters restrictions. (1) If $\theta=\sigma$, i.e. the elasticity of substitution within a sector is equal to the elasticity of substitution between sectors, then the model collapses to the monopolistic case since the price elasticity of demand becomes $\Theta_{t}(i)=\left[\frac{1}{\theta}-0 \cdot \xi(i)\right]^{-1}=\theta=\sigma$ and $\mu_{t}^{\text {desired }}(i)=\frac{\theta}{\theta-1}$. Indeed, since there is an infinity of sectors, if the elasticity of substitution within a sector is equal to the one between sectors, the strategic interactions -that were taking place within a sector- vanish. (2) If the market share $\xi_{t}(i)$ tends to zero (the number of firms goes to infinity for instance), then the market structure also becomes monopolistic with $\Theta(i)=\theta$. (3) If there is only one firm per sector, then $\forall k, \forall i \in \Omega_{t}^{k}: P_{t}^{x}(i)=P_{t}(k)$ and thus $\Theta_{t}(i)=\left[\frac{1}{\theta}-\left(\frac{1}{\theta}-\frac{1}{\sigma}\right) \cdot 1\right]^{-1}=\sigma$.

\subsubsection{Impact of the Market Structure on the Slope of the Phillips Curve}

Loglinearizing equation 2 around a zero inflation steady state with symmetric firms $\left(\forall i, z_{i}=1\right.$ and $\left.P_{t}^{x}(i)=P_{t}^{x}\right)$ leads to an augmented Phillips curve similar to Benigno and Faia (2010) or Bilbiie et al. (2014): ${ }^{17}$

$$
\pi_{t}^{x}=\underbrace{\frac{\Theta_{s s}-1}{\phi_{p}}}_{\text {"slope" }}\left[\hat{m} c_{t}^{x}+\hat{\mu}_{t}^{\text {desired }}\right]+\beta \mathbb{E}_{t} \pi_{t+1}^{x}
$$

\footnotetext{
${ }^{16}$ Note that $\frac{1}{\sigma}-\frac{1}{\theta}>0$ as the elasticity of substitution across goods within a sector is greater than the elasticity of substitution between sectoral goods, and $\forall k, \forall i \in \Omega_{t}^{k}:\left(\frac{P_{t}^{x}(i)}{P_{t}(k)}\right)^{1-\theta} \in(0,1)$. Thus $\sigma<\Theta_{t}(i)<\theta$.

${ }^{17}$ With the difference that there is no exit/entry on the domestic market in my case.
} 
where $\pi_{t}^{x}=\frac{P_{t}^{x}}{P_{t-1}^{x}}$ is the production price inflation, $m c_{t}^{x}=\frac{W_{t}}{A_{t} P_{t}^{x}}$, hat symbol denotes logdeviation from steady state and subscript ${ }_{s} s$ stands for steady state value.

At that point, by incorporating strategic complementarities $(A 1)$ in the new-Keynesian framework, we have learned that inflation reacts less to real marginal cost movements when firms' market power is high (i.e. $\Theta_{s S}$ low). ${ }^{18}$ This is in line with Sbordone $(2010)^{19}$, Benigno and Faia (2010), or Bilbiie et al. (2014). In order to gauge the impact of globalization on firms' steady state market power, I complete the model with two additional assumptions ( $A 2$ and $A 3$ ) in the vein of Melitz (2003) and Chaney (2008).

\subsection{Assumptions A2 and A3: Heterogeneity in Productivity and Endogenous Entry of Exporters}

\subsubsection{Firms are Heterogenous in Productivity}

The productivity $z_{i}$ is given for each firm and does not vary over time. Each variety is produced by only one firm and one firm produces only one variety. Sectors are symmetric: each sector comprises the same number of firms and the same productivity distribution prevails, $\forall k: S^{k}=$ $S=\left\{z_{1}, z_{2}, z_{3}, \ldots, z_{N^{d}}\right\}$. Productivity is ranked by strictly decreasing order: $z_{1}=z_{\max }>z_{2}>$ $z_{3}>. .>z_{N^{d}-1}>z_{N^{d}}=z_{\text {min }}$. Thus, within a sector, a productivity value uniquely pins down a producer (or equivalently a variety). For convenience purpose, in the rest of the paper, I use the productivity type $z$ instead of the variety index $i$ to refer to producers' variables.

\subsubsection{International Trade and Endogenous Entry on the Export Market}

The final consumption good $Y_{t}$ and the sectoral goods $Y_{t}(k)$ are non-tradable, but intermediate goods can be traded. The two countries are identical. They both have their own currency and the nominal exchange rate from $F$ to $D$ is $e_{t} .{ }^{20}$ The real exchange rate is $r e r_{t}=\frac{e_{t} P_{t}^{*}}{P_{t}}$. Prices are set in local currency. In the sector $k$ of country $D$, intermediate inputs incorporated for producing $Y_{t}(k)$ can be supplied either by domestic or foreign firms: $Y_{t}(k)=\left[\sum_{z_{1}{ }^{d}}^{z_{t}} x_{t}^{d}(z)^{\frac{\theta-1}{\theta}}+\sum_{z_{1} f_{t}}^{z_{t}} x_{t}^{f}(z)^{\frac{\theta-1}{\theta}}\right]^{\frac{\theta}{\theta-1}}$,

\footnotetext{
${ }^{18}$ Here the Phillips curve exhibits additional terms on the right-hand side since $\hat{\mu}_{t}^{\text {desired }}$ fluctuates over time, but in the rest of the paper, I stick to the common new-Keynesian meaning of the slope of the Phillips curve, understood as the link between inflation and real marginal cost.

${ }^{19}$ When the markup elasticity dominates the price elasticity term in her setup.

${ }^{20}$ To be read as "one unit of country $F$ currency gives $e_{t}$ units of country $D$ currency".
} 
where the superscripts $d$ or $f$ indicate the origin of goods. ${ }^{21}$ For goods that are consumed in country $\mathrm{F}$, the superscript $d$ or $f$ is followed by a ' $*$ ' symbol, referring to the destination market. ${ }^{22}$

A domestic firm with productivity $z$ can serve the domestic market as well as the foreign market if it is profitable to do so. Since there is no fixed cost for firms to serve their home market, $N^{d}$ is fixed over time because every firm chooses to actually produce and serve its home market.

Firms face a fixed penetration cost on the export market, $f_{X}$, paid in units of consumption. ${ }^{23} N_{t}^{f}$ is the number of intermediate goods produced by foreign firms (and consumed in country $D$ as inputs for a sector $k$ ). $N_{t}^{f}$ varies over time depending on the endogenous export decision of foreign firms. Symmetrically for country $F: N^{f *}$ is fixed over time and $N_{t}^{d *}$ is endogenous. In addition to the fixed market penetration cost $f_{X}$, an exporter also faces a melting-iceberg $\operatorname{cost}(\tau \geq 1)$. To sell one unit of good to the foreign country, an exporter must produce and ship $\tau$ units because $\tau-1$ units melt on the way.

Because of trade costs, markets are segmented and a domestic firm $z$ can set different prices on domestic and foreign markets in order to maximize its total profit. Compared to the homogeneous case in equation 2, the optimal price and markup are firm-specific, depending on the relative productivity factor, $z$. The optimal price set by a domestic firm $z$ on the domestic market is

$$
\begin{aligned}
P_{t}^{d}(z) & =\mu_{t}^{d}(z) \frac{W_{t}}{A_{t} z}, \text { with: } \\
\mu_{t}^{d}(z) & =\frac{\Theta_{t}^{d}(z)}{\left(\Theta^{d} t(z)-1\right)\left[1-\frac{\phi_{p}}{2}\left(\Pi_{t}^{d}(z)-1\right)^{2}\right]+\phi_{p} \Pi_{t}^{d}(z)\left(\Pi_{t}^{d}(z)-1\right)-\Gamma_{t}^{d}(z)}
\end{aligned}
$$

and $\Theta_{t}^{d}(z)$ and $\Gamma_{t}^{d}(z)$ defined in 2 .

For serving the foreign market, the iceberg trade cost scales down firm's effective marginal cost. Firms fix their price in local currency. Hence the optimal price is $P_{t}^{d *}(z)=\mu_{t}^{d *}(z) \tau \frac{W_{t}}{A_{t} z} \operatorname{rer}_{t}^{-1}$. Details of the program are given in Appendix B.

\footnotetext{
${ }^{21}$ And the associated sectoral price becomes $P_{t}(k)=\left[\sum_{z_{1}}^{z_{\mathrm{N}^{d}}} P_{t}^{d}(z)^{1-\theta}+\sum_{z_{1}}^{z_{\mathrm{N} t}} P_{t}^{f}(z)^{1-\theta}\right]^{\frac{1}{1-\theta}}$.

${ }^{22}$ See in Appendix A a summary of the notations. For instance, $x^{d}$ refers to goods produced and consumed in $D$, $x^{d *}$ stands for goods produced in $D$ and sold to $F$, whereas $x^{f *}$ are goods produced and consumed in $F$, and $x^{f}$ are produced in $F$ and consumed in $D$.

${ }^{23}$ Differently from Ghironi and Melitz (2005), I choose the "consumption unit" (instead of effective labor unit) in order to keep the model as transparent as possible and to isolate the mechanisms trough which globalization affects the pricing behavior of firms. For clarity, I don't want the impact of globalization to be driven by a change in fixed costs induced by a move in the real wage, because this effect is of second order compared to the channels I am highlighting. Anyway, as long as the export penetration costs are low enough, the two specifications should predict the same qualitative impact of globalization on the market structure.
} 
For a firm $z$ in country $\mathrm{D}$, the dividend (expressed in units of domestic consumption) is the sum of the profit, in real terms, from sales on the domestic market and the profit from sales on the foreign market: $d_{t}(z)=d_{t}^{d}(z)+d_{t}^{d *}(z)$, where:

$$
\begin{aligned}
& d_{t}^{d}(z)=\left[1-\frac{1}{\mu_{t}^{d}(z)}-\frac{\phi_{p}}{2}\left[\Pi_{t}^{d}(z)-1\right]^{2}\right] x_{t}^{d}(z) \frac{P_{t}^{d}(z)}{P_{t}} \\
& d_{t}^{d *}(z)= \begin{cases}0 & \text { if the firm does not export. } \\
\operatorname{rer}_{t}\left[1-\frac{1}{\mu_{t}^{d *}(z)}-\frac{\phi_{p}}{2}\left[\Pi_{t}^{d *}(z)-1\right]^{2}\right] x_{t}^{d *}(z) \frac{P_{t}^{d *}(z)}{P_{t}^{*}}-f_{X} & \text { otherwise. }\end{cases}
\end{aligned}
$$

\subsubsection{Sequential Entry of Exporters}

In the rest of the paper, I follow Atkeson and Burstein (2008) and restrict to sequential entry. Suppose that firms are ranked by decreasing order of productivity (as in $S$ ) and consider entry sequentially. $^{24}$

Say that the $n^{\text {th }}$ most productive firms are already exporters, then the $n+1^{\text {th }}$ firm in $S$ can choose wether it is profitable to pay the export penetration cost. If it is profitable to do so, then the next $n+2^{\text {th }}$ firm in $S$ can decide. And so on and so forth. When the profit of the $n+j^{\text {th }}$ most productive firm turns out negative, then the equilibrium is reached and involves the $n+j-1$ most productive firms being active in international trade. By definition, $N_{t}^{d *}$ is the number of exporters at time $t$. Thus the cutoff productivity (that pins down the least productive exporter) is denoted $z_{N_{t}^{d *}}$. By construction, all firms more productive than $z_{N_{t}^{d *}}$ are exporters too. And firms below the threshold are not.

\subsection{Closing the General Equilibrium and Solving for the Steady State}

I aim at comparing the short-run responsiveness of inflation to marginal cost around a pre-globalization steady state -high $\tau$ - and a post-globalization steady states -low $\tau$. This new-Keynesian Phillips curve relationship is a partial equilibrium object. ${ }^{25}$ However I need to solve for the whole general equilibrium (in steady state) in order to pin down the steady state market power of firms that determines the slope of the Phillips curve.

This technical part is reported in Appendix and involves two steps: (i) closing and defining

\footnotetext{
${ }^{24}$ As noticed by Atkeson and Burstein (2008), this is one among many other potential equilibria.

${ }^{25}$ The general equilibrium relationship between inflation and domestic slack might also be affected by monetary policy, inflation expectations, etc.
} 
the general equilibrium (see Appendix C), and (ii) solving for the steady state (in Appendix D). Compared to the previous literature that incorporates oligopolistic competition $(A 1)$ in a newKeynesian framework, the steady state of my model is a bit more complicated to solve due to heterogeneity across firms $(A 2)$. This is the reason why I dedicate a full Appendix section to the computation of the steady state equilibrium.

With those tools in hands, I am able to determine the steady state for different values of iceberg trade costs, $\tau$. When $\tau$ falls, the set of firms involved in international trade expands. Next section provides analytical results characterizing how the dynamics of inflation evolves when the steady state market structure changes.

\section{Analytical Results on the New-Keynesian Phillips Curve}

The goal of this section is to compare the dynamics of the short-run inflation around the preglobalization steady state (high $\tau$ ) and the post-globalization state (low $\tau$ ). A decline in the sensitivity of inflation to marginal cost has been observed in the data ${ }^{26}$ and I show that a drop in the iceberg trade cost, $\tau$, can generate the same feature in my model. As firms are different in terms of productivity and consequently in size and in market power, they adjust their optimal price differently. To shed light on the domestic inflation dynamics, I aggregate those heterogeneous price adjustment behaviors. Results regarding the firm-level price adjustment dynamics are derived in sub-section 3.1. The impact of globalization on the aggregate Phillips curve is discussed in subsection 3.2.

\subsection{Dynamics around the Steady State for an Individual Firm $z$}

Loglinearizing the actual markup $\mu_{t}^{d}(z)$ from equation (4) around the steady state gives the augmented Phillips curve in (5). Note that in this section, I refer to the Phillips curve in a loose way since I am considering firm-level behaviors whereas the Phillips curve commonly refers to the dynamics of inflation at the aggregate level. This terminology abuse aims at highlighting the link between aggregate results and the micro-foundations.

\footnotetext{
${ }^{26}$ See for instance Matheson and Stavrev (2013) or Blanchard et al. (2015).
} 


$$
\pi_{t}^{d}(z)=-\frac{\Theta_{s S}^{d}(z)-1}{\phi_{p}}\left[\hat{\mu}_{t}^{d}(z)-\hat{\mu}_{t}^{d, \text { desired }}(z)\right]+\beta \mathbb{E}_{t} \pi_{t+1}^{d}(z)
$$

Then,

$$
\pi_{t}^{d}(z)=\frac{\Theta_{s S}^{d}(z)-1}{\phi_{p}}\left[\hat{m} c_{t}^{d}(z)+\hat{\mu}_{t}^{d, \text { desired }}(z)\right]+\beta \mathbb{E}_{t} \pi_{t+1}^{d}(z)
$$

where $\hat{m} c_{t}^{d}(z)=\hat{W}_{t}-\hat{A}_{t}-\hat{P}_{t}^{d}(z)=\hat{w}_{t}-\hat{A}_{t}-\hat{p}_{t}^{d}(z)$ and the desired markup is not constant

and fluctuates with the price elasticity of demand: $\mu_{t}^{d \text {,desired }}(z)=\frac{\Theta_{t}^{d}(z)}{\Theta_{t}^{d}(z)-1}$, so that $\hat{\mu}_{t}^{d, \text { desired }}(z)=$ $-\frac{1}{\Theta_{s S}^{d}(z)-1} \hat{\Theta}_{t}^{d}(z)$. Thus:

$$
\pi_{t}^{d}(z)=\frac{\Theta_{s s}^{d}(z)-1}{\phi_{p}} \hat{m} c_{t}^{d}(z)-\frac{1}{\phi_{p}} \hat{\Theta}_{t}^{d}(z)+\beta \mathbb{E}_{t} \pi_{t+1}^{d}(z)
$$

Equation 7 resembles closely the one presented in section 2.2.2, but it holds at the firm level. The same key properties are verified: the sensitivity of price adjustments to marginal cost depends negatively on a firm's steady state market power, and cyclical adjustments in the desired markup influence price adjustments. But the steady state demand elasticity, $\Theta_{s S}^{d}(z)$, varies for different producers, depending on their relative productivity. Thus price adjustments respond differently to marginal cost fluctuations for each producer. Most productive firms have a larger market share and exhibit a flatter Phillips curve as $\Theta_{s S}^{d}(z)$ is low. They are less prone to transmit marginal cost fluctuations into inflation compared to smaller firms. Intuitively, larger firms are the ones who are the most concerned about losing market share as the markup elasticity to relative prices is increasing in the market share. Therefore, the real rigidities are increasing with firm size, and the pass-through of marginal cost into inflation declines.

\section{Proposition 1. (Cyclical fluctuations in the price elasticity of demand matter for inflation dy- namics)}

In a sticky price environment à la Rotemberg, under oligopolistic competition, individual firm inflation depends positively on changes in the real marginal cost and on inflation expectations and negatively on the cyclical fluctuations in the perceived price-elasticity of demand, $\hat{\Theta}_{t}^{d}$. A decline in $\hat{\Theta}_{t}^{d}$ should be interpreted as a strengthening of firm's market power, which pushes up inflation. Conversely, an increase in $\hat{\Theta}_{t}^{d}$ reduces inflation.

Proof. See equation (7).

The short-run fluctuations in the price elasticity of demand are positively related to the firm 
relative price.

$$
\hat{\Theta}_{t}^{d}(z)=-\frac{\left(\frac{1}{\sigma}-\frac{1}{\theta}\right) \xi_{s S}^{d}(z)}{\Theta_{S S}^{d^{3}}(z)} \hat{\xi}_{t}^{d}(z)=-\frac{\Theta_{S S}^{d}{ }^{-1}(z)-\theta^{-1}}{\Theta_{S S}^{d^{3}}(z)} \widehat{\xi}_{t}^{d}(z)=\frac{\Theta_{S S}^{d-1}(z)-\theta^{-1}}{\Theta_{S S}^{d^{3}}(z)}(\theta-1) \hat{p}_{t}^{d}(z)
$$

Thus

$$
\pi_{t}^{d}(z)=\frac{\Theta_{s s}^{d}(z)-1}{\phi_{p}} \hat{m} c_{t}^{d}(z)-\frac{1}{\phi_{p}} \frac{\Theta_{s s}^{d}{ }^{-1}(z)-\theta^{-1}}{\Theta_{s S}^{d}(z)}(\theta-1) \hat{p}_{t}^{d}(z)+\beta \mathbb{E}_{t} \pi_{t+1}^{d}(z) .
$$

\section{Corollary 1. (Cyclical fluctuations in the competitive pressures matter for inflation dynamics)}

In a sticky price environment à la Rotemberg, under oligopolistic competition, individual firm short-run inflation is decreasing in its relative price (that captures the fluctuations in the perceived competitive pressures).

Proof. See equation (8). An increase in the relative price is equivalent to a strengthening in competitive pressures faced by a firm. Conversely, a decline in the relative price corresponds to alleviating competitive pressures, which pushes up inflation.

The previous Proposition 1 and the associated Corollary 1 describe the determinants of the short-run inflation dynamics at the firm level. Importantly, the weights on each factor (marginal cost and relative price) are firm-specific. Note that the coefficient governing the sensitivity of inflation to the relative price is the steady state demand elasticity with respect to the relative price. Indeed, denoting $\varepsilon_{u, v}$ the elasticity of variable $u$ with respect to $v$, I get:

$$
\varepsilon_{\mu, p^{x}}=\underbrace{-\frac{1}{\Theta_{S S}^{x}-1}}_{\mathcal{\varepsilon}_{\mu, \Theta}} \underbrace{\left(-\frac{\frac{1}{\Theta_{S S}^{x}}-\frac{1}{\theta}}{\Theta_{S S}^{x^{3}}}\right)}_{\varepsilon_{\Theta, p^{x}}} \underbrace{(1-\theta)}_{\varepsilon_{\Theta, \tilde{\xi}}}
$$

Thus equation (8) becomes:

$$
\pi_{t}^{d}(z)=\overbrace{\frac{\Theta_{S S}^{d}(z)-1}{\phi_{p}}}^{\text {high for small firms }} \hat{m} c_{t}^{d}(z)-\overbrace{\frac{1}{\phi_{p}} \varepsilon_{\Theta, p^{d}}(z)}^{\text {high for large firms }} \hat{p}_{t}^{d}(z)+\beta \mathbb{E}_{t} \pi_{t+1}^{d}(z)
$$

The term $\varepsilon_{\mu, p^{x}}$ connects this paper to the literature studying real rigidities in a flexible prices environment, as Amiti et al. (2015). In the long run, nominal rigidities vanish and the model yields similar predictions: the markup elasticity with respect to the relative price $\left(\varepsilon_{\mu, p^{x}}\right)$ is increasing in 
market share. And the markup elasticity with respect to the nominal price is a hump-shaped function in the market share. It is zero for infinitely small firms. Then the markup elasticity increases with firm's market share. Ultimately, for firms that are sufficiently large (almost monopoly in their sector), the elasticity decreases as they end up competing against the continuum of other sectors (instead of competing with other firms within their sector). ${ }^{27}$

Differently from the flexible prices literature, the focus of this paper is on the short-run fluctuations of inflation. But the long-run degree of real rigidities (i.e. the steady state market power of firms) pinpoints the short-run dynamics.

\section{Proposition 2. (The steady state price elasticity of demand perceived by a firm pins down the} sensitivity of price adjustment to marginal cost)

Under oligopolistic competition with sticky prices à la Rotemberg, the lower a firm steady state price elasticity of demand (or equivalently the higher its market power), the less reactive the price adjustement to marginal cost fluctuations.

Proof. See equation 10. The coefficient pondering the real marginal cost term is the slope of the new-Keynesian Phillips curve.

Noting that the steady state market share of a firm is increasing in its productivity type $z$, the previous proposition can be re-stated as follows:

\section{Corollary 2. (Large firms exhibit a flatter individual Phillips curve)}

High-productivity firms are larger and exhibit a flatter Phillips curve compared to less productive (also smaller) firms.

Proof. The sensitivity of inflation to marginal cost is increasing in the steady state price elasticity of demand, and the latter is decreasing in firm's productivity.

Section 3.1 has emphasized that the sensitivity of price adjustment to real marginal cost is lower for large firms. Consequently, at the aggregate level, the link between domestic inflation and real marginal cost depends on the proportion of big versus small firms producing domestic output.

\footnotetext{
${ }^{27}$ Precisely, for the benchmark parameterization of the model, the turning point -after which the markup elasticity starts decreasing as a function of the market share- is $\xi \simeq 95 \%$. With the productivity distributions I am considering in the calibration, no firm can actually be that big. Thus, the markup elasticity can be thought of as monotonically increasing in firm size, which is consistent with Berman et al. (2012), Garetto (2014), or Amiti et al. (2015) empirical findings.
} 


\subsection{The Aggregate Phillips Curve}

This section shows how the aggregate domestic Phillips curve can be constructed from individual behaviors. I focus on "domestically produced" inflation, i.e. measured as the percentage change in the Gross Domestic Product (GDP) deflator. Indeed, most empirical studies ${ }^{28}$ rely on GDP deflator inflation for structural Phillips curve estimates. Very close to my approach, Imbs et al. (2011) and Leith and Malley (2007) use the output deflator inflation to estimate disaggregated Phillips curves at the sector level. Besides, Coibion and Gorodnichenko (2015) show that the change in slope (flattening) of the Phillips curve is statistically significant across all their specifications when inflation is measured with the GDP deflator whereas results are less clear when using CPI inflation. Hence I am focusing on GDP deflator Phillips curve in order to be consistent with the aforementioned empirical works. ${ }^{29}$

The GDP deflator is defined as the price of total net output of resident producers: $P_{t}^{G D P}=$ $\frac{N G D P_{t}}{R G D P_{t}}$, with the nominal GDP at time $t$ computed using that quarter's prices $\left(N G D P_{t}=\sum_{z_{1}}^{z^{d}} P_{t}^{d}(z) x_{t}^{d}(z)+\right.$ $\left.\sum_{z_{1}}^{z_{N}^{d *}} P_{t}^{d *}(z) x_{t}^{d *}(z) e_{t}\right)$, and the real GDP computed using the base quarter's prices ${ }^{30}\left(R G D P_{t}=\right.$ $\left.\sum_{z_{1}}^{z_{N}^{d}} P_{s s}^{d}(z) x_{t}^{d}(z)+\sum_{z_{1}^{d *}}^{z_{N_{s}^{d *}}} P_{s s}^{d *}(z) x_{t}^{d *}(z)\right)$. Note that all produced varieties $x_{t}(z)$ can be interpreted as final demand goods since they immediately enter in the final consumption bundle. ${ }^{31}$ Thus, in this framework, the price of GDP (i.e. the total net output of resident producers) is approximately equal to the price of gross output (i.e. the Production Price Index). ${ }^{32}$

In this paper, I want to compare the short-run dynamics of inflation around two steady states: a pre-globalization steady state, characterized by high iceberg trade costs and almost no trade; and a post-globalization steady state, characterized by lower per-unit trade costs and greater openness

\footnotetext{
${ }^{28}$ See for instance Gali and Gertler (1999), Matheson and Stavrev (2013), or Blanchard et al. (2015)

${ }^{29}$ Another more theoretical reason for my choice is related to the very mechanism I am trying to establish. For the purpose of understanding the impact of market structure on inflation dynamics, it is more transparent to focus on the response of prices to the same marginal cost shock (hence restricting to resident firms' behavior only). Looking at CPI-inflation Phillips curve sheds light on the global slack hypothesis since part of the CPI-inflation is driven by the behavior of foreign firms (that show up implicitly in imported goods). This introduces a link between domestic inflation and foreign slack, which is obviously a very important channel, but different from the one I am interested in. My point is to show why prices' adjustments by domestic firms have become less responsive to domestic slack. Hence I want to relate inflation to a measure of domestic slack, not a combination of domestic and foreign slack.

${ }^{30}$ Here the steady state values.

${ }^{31}$ Recall that labor is the only input in the production function. There are no intermediate goods used in the production of $x_{t}(z)$.

${ }^{32}$ The coverage is the same: the prices of all goods produced by domestic (resident) firms, either for serving the domestic or the foreign market. But the difference lies in the way the indices are constructed: the GDP deflator is a Paasche index while the PPI is a Laspeyres index. Yet, at the first order, when considering the log-deviation of inflation measured by either of these indices, they are equivalent. For more details, see J. Weinhage (2014), "Comparing new final-demand producer price indexes with other government price indexes," Monthly Labor Review, BEA, January.
} 
to trade. When comparing those two steady states, the fall in iceberg trade cost is large enough for the market structure to adjust ( $N_{s s}^{d *}$ grows from the pre-globalization steady state to the postglobalization state). Hence the GDP deflator composition is modified between the two steady states. But as far as the cyclical fluctuations around the steady state are concerned, the set of exporting firms is kept constant $\left(N_{t}^{d *}=N_{s s}^{d *}\right.$ in the neighborhood of the steady state).

Why is it so? First, because contrary to Ghironi and Melitz (2005), Jaimovich and Floetotto (2008), or Bilbiie et al. (2014), the entry/exit of firms is not a continuous process. Here, the set of firms is discrete and the number of exporters 'jumps' from an integer to the next one when the profitability threshold is reached. Thus, it is not necessarily the case that the market structure changes when economy is hit by a shock. I consider that only globalization is a big enough shock to trigger a change in the market structure. But the aggregate stochastic perturbations around the steady state do not modify the set of exporting firms. Second, more generally, I aim at explaining the impact of globalization, which is a massive phenomenon that has deeply modified the market structure over a long period of time -the last twenty/thirty years-. The fluctuations in the number of varieties in the short run are not of the same order of magnitude, and even though they certainly matter, they are not my object of interest here. That is the reason why, keeping the set of firms active in international trade fixed around a given steady state makes sense in that context. Third, assuming a fixed set of firms around the steady state is consistent with the actual price index construction by statistical agencies. Typically, the weights for the production price index in the United States are updated every five years. In between (i.e. at the business cycle frequency), the sample of goods is kept constant.

Writing the output deflator in log deviation and taking the difference from $t-1$ to $t$ gives the inflation rate: $\pi_{t}^{g d p}=\sum_{z_{1}}^{z_{N}} \xi_{s s}^{d}(z) \pi_{t}^{d}(z)+\sum_{z_{1}^{N}}^{z d_{s s}^{*}} \xi_{s s}^{d *}(z)\left(\pi_{t}^{d *}(z)+\Delta \hat{e}_{t}\right)$

Inflation is a sales-weighted average of the changes in individual prices charged by domestic firms (and eventually sold either on the domestic or on the foreign market). ${ }^{33}$ Now, plugging the firmspecific Phillips curves into the previous equation gives a link between aggregate domestic inflation, $\pi_{t}^{g d p}$, and domestic firms' marginal cost. Importantly, there are no idiosyncratic shocks that might affect the relative productivity factor of individual firms. Thus, the marginal cost fluctuations are the same for all residents from the same country, independently of their relative produc-

\footnotetext{
${ }^{33}$ Because of symmetry across countries, the steady-state weight of an exporter in domestic sales is equal to its market share in the foreign country, $\xi_{s s}^{d *}(z)$.
} 
tivity.

The aggregate Phillips curve becomes:

$$
\pi_{t}^{g d p}=\beta \mathbb{E}_{t} \pi_{t+1}^{g d p}+\Psi\left(N_{s s}^{d *}\right) \hat{m} c_{t}-\mathrm{RP}_{t}+\text { Exch. Rate } \text { R }_{t}
$$

where

$$
\begin{aligned}
& \hat{m c} c_{t}=\hat{W}_{t}-\hat{A}_{t}-\hat{P}_{t} \\
& \Psi\left(N_{s s}^{d *}\right)=\sum_{z_{1}}^{z_{N^{d}}} \xi_{s s}^{d}(z) \frac{\Theta_{s S}^{d}(z)-1}{\phi_{p}}+\sum_{\overline{z_{1}}}^{z_{N_{s s}^{d *}}} \xi_{s s}^{d *}(z) \frac{\Theta_{s s}^{d *}(z)-1}{\phi_{p}} \\
& \mathrm{RP}_{t}=\left\{\begin{array}{c}
\sum_{z_{1}}^{z_{N}} \frac{\xi_{s s}^{d}(z)}{\phi_{p}}\left(\frac{\Theta_{s s}^{d}(z)^{-1}-\theta^{-1}}{\Theta_{s s}^{d}(z)^{3}}+\frac{\Theta_{s s}^{d}(z)-1}{\theta-1}\right)(\theta-1) \hat{p}_{t}^{d}(z) \\
+\sum_{z_{1}}^{z_{N_{s}^{d *}}^{d *}} \frac{\xi_{s s}^{d *}(z)}{\phi_{p}}\left(\frac{\Theta_{s s}^{d *}(z)^{-1}-\theta^{-1}}{\Theta_{s s}^{d * 3}}+\frac{\Theta_{s s}^{d *}(z)-1}{\theta-1}\right)(\theta-1) \hat{p}_{t}^{d *}(z) \\
z_{N_{s s}^{d *}}
\end{array}\right. \\
& \text { Exch. Rate }{ }_{t}=\sum_{z_{1}} \xi_{s s}^{d *}(z)\left(\frac{\Theta_{s s}^{d *}(z)-1}{\phi_{p}} r \hat{e} r_{t}+\Delta \hat{e}_{t}\right) .
\end{aligned}
$$

Proposition 3. If fixed export penetration costs are large enough, and iceberg trade costs low enough, then, by self-selection, the steady state average size of domestic firms on the export market is larger than the average size of the whole population of domestic firms on the domestic market.

Proof. Define the average market share of domestic firms on the domestic market as $\widetilde{\xi_{S S}^{d}}=\frac{1}{N^{d}} \sum_{z_{1}^{d}}^{z_{N^{d}}} p_{s s}^{d(1-\theta)}(z)$ and the average market share of domestic firms on the export market as $\widetilde{\xi_{s s}^{d *}}=\frac{1}{N_{s s}^{d *}} \sum_{z_{1}}^{z_{s s}^{d *}} p_{s s}^{d *}(1-\theta)(z)$. First, for a given exporting firm with productivity $z$, its market share on the foreign market is always lower than on the domestic market. Indeed, if $\tau>1$, then $\xi_{s s}^{d}(z)>\xi_{s s}^{f}(z)$.

But, for a cutoff productivity $z_{N_{s s}^{d *}}$ sufficiently high (i.e. $f_{X}$ high enough), the higher average productivity of exporters offsets the negative effect of the iceberg trade cost (that penalizes their effective marginal cost on the foreign market). In the end, for $f_{X}$ 'sufficiently high' and $\tau$ 'sufficiently low', then the average relative price of traded goods is lower than non-traded goods because they are produced by much more productive firms. Hence the average market share of firms on the export market is higher than the market share of the whole set of domestic firms on their home market.

The following figures 1 to 6 illustrate that point. In this example, there are 50 domestic firms 


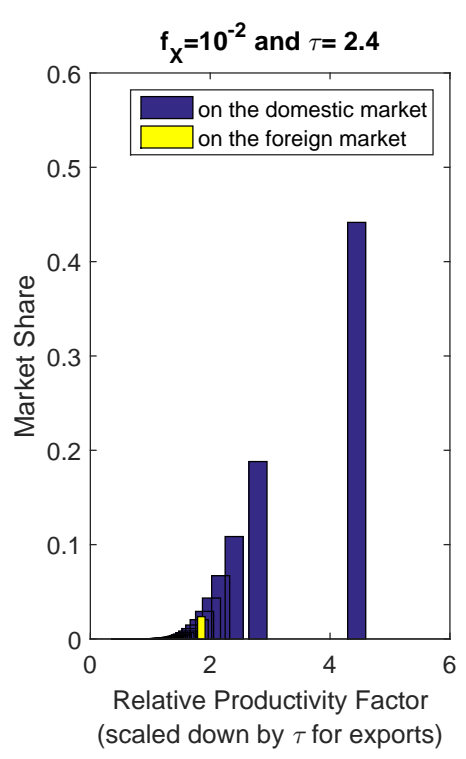

Figure 1:

$\tilde{\xi}^{d}=0.02$ and $\tilde{\xi}^{f}=0.02$

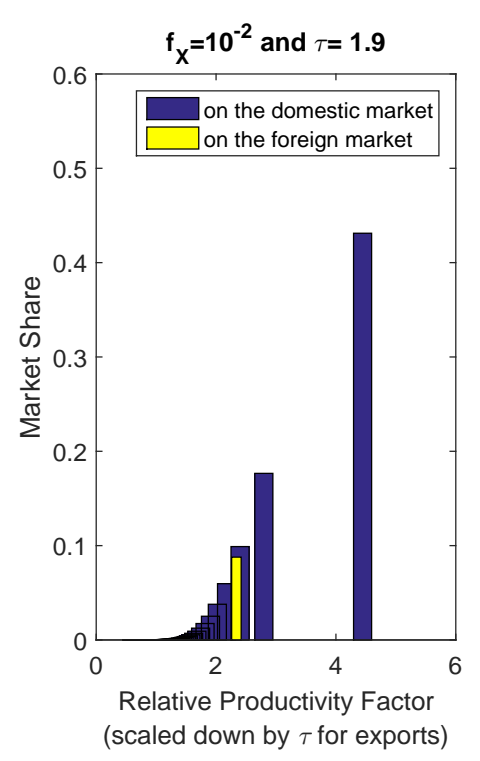

Figure 2:

$\tilde{\xi}^{d}=0.02$ and $\tilde{\xi}^{f}=0.09$

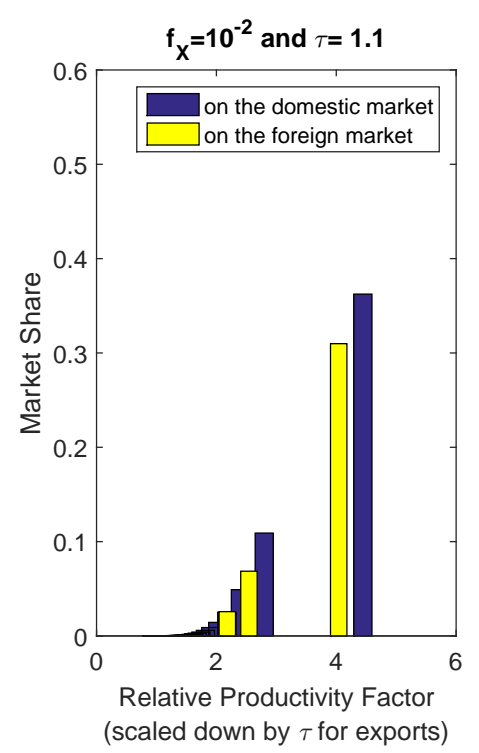

Figure 3:

$\tilde{\xi}^{d}=0.02$ and $\tilde{\xi}^{f}=0.13$

per sector, represented by 50 blue bars whose height corresponds to firm's market share. On the $y$-axis, we read the market share of firms on their domestic market (blue bars), and on the foreign market (yellow bars). The $\mathrm{x}$-axis gives the effective productivity factor of firms ( $z$ or $z$ divided by $\tau$ for exports). Hence, the first yellow bar on the right represents the market share of the most productive domestic firm on the export market. In the first panel (figures 1 to 3 ), $f_{X}$ is high and only a few very productive firms do export. From the left to the right, the iceberg trade cost is decreasing. When $\tau$ is high, then the most productive firm only gets a small market share on the foreign market (thus low market power). But as $\tau$ declines, the average market share on the export market becomes higher than on the domestic market. This comes from exporters being very different from the whole population (i.e. much more productive). Yet, that would not necessarily be the case if $f_{X}$ were lower and the set of exporters broader.

In the second panel (figures 4 to 6 ), $f_{X}$ is low and thus the set of exporting firms is larger, which, as a corollary, implies that exporters are marginally less and less productive. When the per-unit trade $\cos t \tau$ falls, the set of exporters enlarges in such a way that the average market share on the export market becomes smaller than on the domestic market (many exporters are not even visible in figures 4 to 6 because their market share is too small ). 


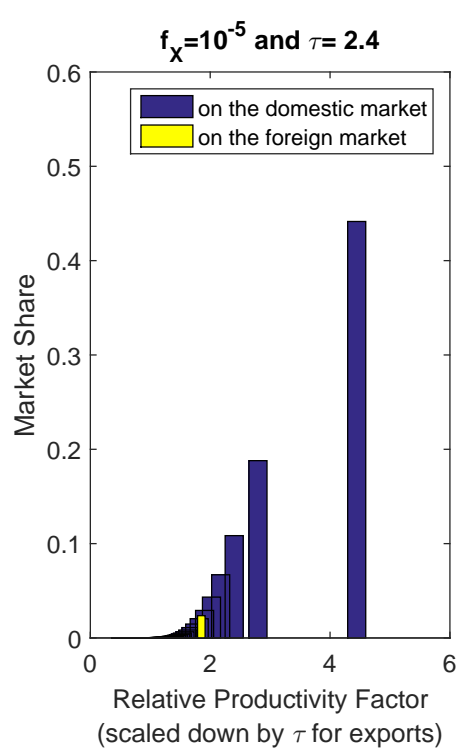

Figure 4:

$\tilde{\xi}^{d}=0.019$ and $\tilde{\xi}^{f}=0.006$

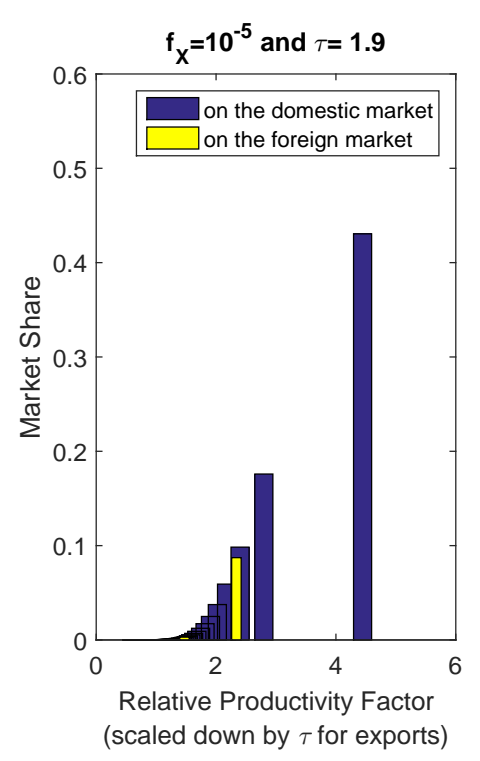

Figure 5:

$\tilde{\xi}^{d}=0.018$ and $\tilde{\xi}^{f}=0.010$

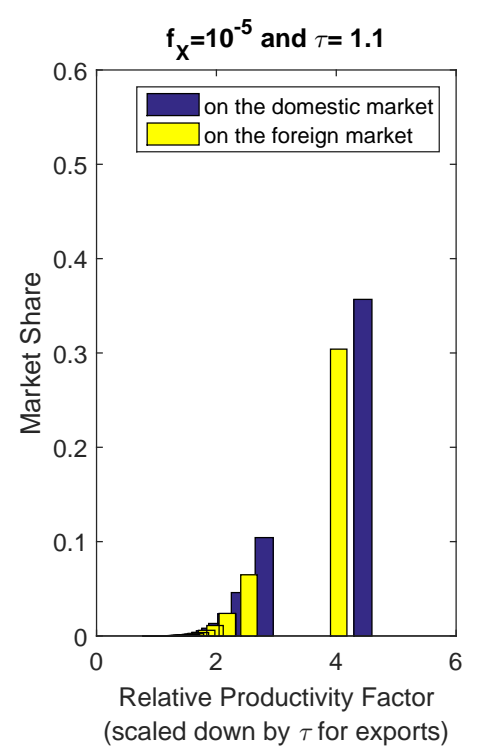

Figure 6:

$\tilde{\xi}^{d}=0.012$ and $\tilde{\xi}^{f}=0.011$

This result is really key for understanding the impact of globalization on the Phillips curve slope. Since globalization is modeled as a fall in trade costs with an endogenous selection of exporters, then the "average market power" in the domestic economy might strengthen if the relative proportion of big firms increases. If the concentration force dominates, then inflation reacts less to demand slack. All in all, the slope of the Phillips curve depends on the composition of the economy, i.e. the size-distribution of firms producing domestic output and their market power. Even though the distribution of productivity is fixed over time, the share of domestic production supplied by each firm may vary depending on the export decision of firms. The relative proportion of big versus small firms producing domestic output determines the dynamics of inflation.

\section{$4 \quad$ Numerical Example}

\section{Proposition 4. (The aggregate Phillips curve can flatten in response to globalization)}

The responsiveness of inflation to real marginal cost, defined in equation (11) as $\Psi\left(N_{s s}^{d *}\right)$ can decrease in response to globalization for a parametrization of the model that replicates standard features of international trade.

Proof. see Numerical Example. 


\subsection{Calibration}

Part of the parameters are very standard in new-Keynesian setups. Regarding nominal rigidities, standard results in the literature estimate a duration of prices equal to three quarters, corresponding to a probability of being unable to re-optimize a price in the Calvo setup $\alpha=0.66$. I choose the price adjustment cost in order for the Phillips curve slope in the Rotemberg setup to match the Phillips curve slope arising in models à la Calvo. So I impose $\phi_{p}$ to be such that

$$
\underbrace{\frac{\theta-1}{\phi_{p}}}_{\text {Rotemberg PC slope }}=\underbrace{\frac{(1-\alpha)(1-\alpha \beta)}{\alpha}}_{\text {Calvo PC slope }} .
$$

Consequently I derive $\phi_{p}=28$. As I am interested in the change of the Phillips curve slope before and after globalization, this parameter doesn't influence my conclusions. It scales up or down the slope of the Phillips curve, but the relative change caused by globalization is unaffected.

Regarding the distribution of firms' relative productivity, I adapt Ghironi and Melitz (2005) framework into a finite-number-of-firms environment. The discrete distribution comes from discretizing an underlying truncated Pareto distribution with scale parameters $\zeta_{\min }=1$ and $\zeta_{\max }=6$. The shape parameter $k$ is set following Ghironi and Melitz (2005): $k=3.4$. Note that $\zeta_{\max }$ is such that, for a non bounded Pareto distribution, $\mathbb{P}\left(Z \geq \zeta_{\max }\right)<0.01$. Appendix $\mathrm{F}$ describes how $\mathrm{I}$ discretize the truncated Pareto Distribution for a given number of firms per sector. The number of firms per sector is $N^{d}=50$. Since the distribution of firms is discrete, there is a tradeoff between (i) choosing $N^{d}$ sufficiently high, in order to have enough high productivity firms (thus, when the set of exporters expands, new exporters are still very different from the overall population), and (ii) keeping $N^{d}$ 'small enough' for strategic interactions to arise.

As far as the elasticity of substitution is concerned, I set $\theta=10$ and $\sigma=1.01$ as in Atkeson and Burstein (2008). This is consistent with Anderson and van Wincoop (2004) who find that the inter-sectoral elasticity of substitution lies between 5 and 10 .

I model globalization as a permanent fall in iceberg costs $\tau$. The per-unit trade cost may reflect different type of barriers to trade. Table 1 presents the range of values for $\tau$ in the literature. 
Table 1: Per Unit Iceberg Costs in the Literature

\begin{tabular}{ccc}
\hline & value range & target \\
\hline \hline Atkeson and Burstein (2008) & {$[1.34 ; 1.58]$} & exports to GDP ratio $=16.5 \%$, exporting \\
firms $=25 \%$
\end{tabular}

These values correspond to the post-globalization steady state in my framework, when the economy is open. For comparison with the pre-globalization economy, I consider a large fall in the iceberg trade costs from 2.5 to 1 and I compute the steady state set of exporters for each value of $\tau$. This range corresponds to a share of domestic goods in the domestic consumption basket equal to 1 pre-globalization (for $\tau=2.5$ ); 0.8 post-globalization (for $\tau=1.45$ ) and 0.53 in the extreme case where $\tau=1$. $f_{X}=0.01$ is chosen such that openness to trade is around $80 \%$ post-globalization. This figure lies in between the US and European countries (imports to GDP ratio is around 15\% in the US and close to $24 \%$ in the Euro Area excluding intra-euro trade -a bit more than $40 \%$ when intra-euro trade is incorporated).

The number of exporters goes from zero to three (out of 50 firms) in the extreme case where $\tau=1$ (see Figure 7). The number of exporting firms might seem very low in this calibration. Yet, I claim that this is consistent with empirical findings regarding exporters. Bernard et al. (2007) find that only $4 \%$ out of 5.5 million of U.S. firms in 2000 are exporters. Besides, among exporters, the top $10 \%$ account for 96 percent of U.S. exports. Since my model is very stylized, it should be understood that I am focusing on these $10 \%$ out of the $4 \%$ exporting firms, that are really 'superstar exporters'. In that perspective, the small number of exporters makes sense. ${ }^{34}$

\footnotetext{
${ }^{34}$ I acknowledge that studies restricting to manufacturing industries -more involved in trade- find higher estimates of the share of exporters, around 15\%-20\% for U.S. firms and about the same for French firms in Eaton et al. (2011). However: (i) Among those exporters, only a very few of them account for a bulk of all exports. Hence, in a very stylized environment, it makes sense to focus on the impact of those superstars that matter the most. (ii) My model does not restrict to manufacturing, but also incorporates the behavior of large firms in other sectors involved in international trade. In that context, the share of exporters can be low.
} 


\subsection{Example}

Figure 7 shows the change in the sensitivity of inflation to real marginal cost (i.e. the slope of the Phillips curve) under two specifications. The solid blue line represents the responsiveness of inflation to demand pressures (i.e. $\Psi\left(N_{s s}^{d *}\right)$ ) when firms are heterogeneous in productivity and thus the high-productivity firms' self-selection mechanism is at play. The red line stands for the slope of the Phillips curve in an economy that exhibits the same average productivity, but in which all firms are homogeneous in productivity. For sake of comparison, I impose the number of firms in the homogeneous productivity economy to be the same as in the heterogeneous economy, for each value of $\tau$. Hence the pro-competitive channel, due to the enlargement in the set of competitors, is at work in the homogeneous productivity economy, but the re-allocation/concentration effect (due to self-selection of large firms in international trade) is shut down.

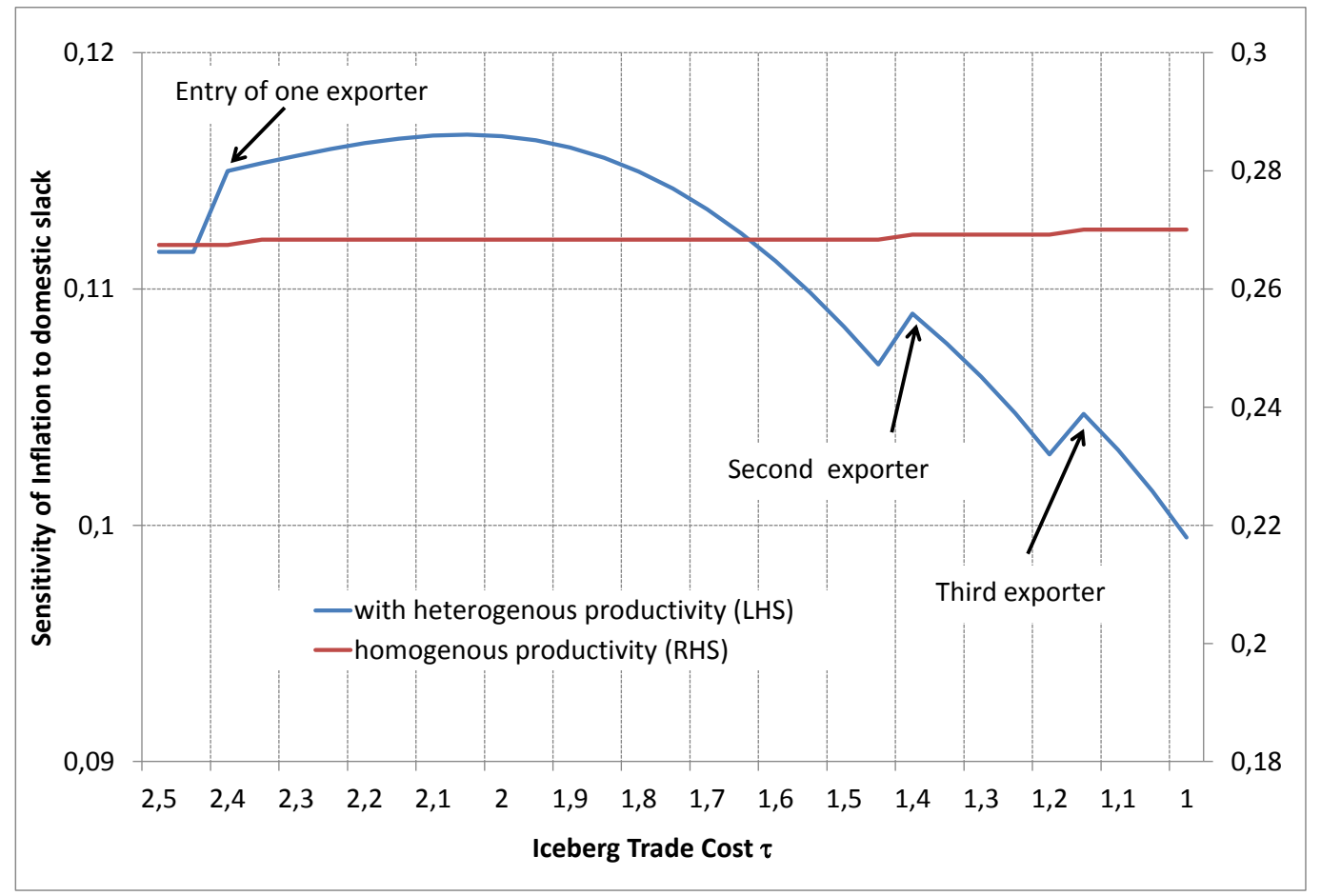

Figure 7: Phillips Curve Slope $\Psi\left(N_{s s}^{d *}\right)$

Two results are brought to light. First, for a same average productivity, the economy with 
homogeneous firms exhibits a much higher responsiveness of inflation to marginal cost than the economy with heterogeneous firms. This result highlights the crucial non-linearities in the model. Large firms play a very important role in driving the response of inflation to domestic slack: when firms are heterogeneous, granularity matters. Second, the slope of the Phillips curve responds in opposite direction to globalization in the two economies. In the heterogeneous productivity case, inflation becomes less reactive to marginal cost because the concentration effect (self-selection of big firms) offsets the pro-competitive effect. Shutting down the re-allocation channel -that makes economy more granular- causes inflation to react more to domestic slack. The simulation predicts that the slope of the aggregate Phillips curve would slightly increase (by 1\%) if only the pro-competitive channel were active. Once the re-allocation/concentration channel is added, then the sensitivity of inflation to marginal cost drops by $11 \%$.

However those results should really be interpreted as illustrative of a potential impact of globalization rather than taken as a quantitative evaluation. Indeed, the model is extremely stylized and impose the very strong assumption that sectors are symmetric. Besides, wether the proconcentration or the pro-competitive force dominates depends heavily on the distribution of productivity and the number of firms. In a symmetric country environment, exporters gaining market power abroad implies domestic firms loosing some on the domestic market. The overall impact on the average market power of resident producers depends in the end on the deformation of the market share distribution. Hence, the quantitative assessment about which effect prevails in different sectors/countries ultimately remains an empirical question that is left for future research. Here, the main contribution is to uncover the role of the pro-concentration force in shaping inflation dynamics. The previous literature was only focusing on the pro-competitive effect whereas this paper shows that ( $i$ ) the flattening of the Phillips curve can be rationalized by the pro-concentration force, and (ii) a fall in international per-unit trade costs might favor greater concentration.

Importantly, the only force driving the increase in the average market power (and incidently the decline in the slope of the Phillips curve) in the model is a composition effect: the weight of exporters in the economy increases and exporters charge significantly higher markups than the average population of firms. This composition effect might stem either (i) from the intensive or (ii) from the extensive margin of exports. (i) First, holding the set of exporters constant, the decline in per-unit trade costs increases their relative productivity on the foreign market, which increases their market share/market power. (ii) Second, new firms start exporting. Those firms are among 
the most productive and the biggest ones, and charge high markups even on the export market. Hence, the weight of "high market power" producers in domestic production increases.

The theoretical results and the subsequent numerical example sum up as follows. Large firms do less transmit marginal cost shocks into price adjustments. Besides, the weight of large firms in domestic production increases. Hence, in the aggregate, as economy becomes more concentrated, inflation responds less to domestic slack. Next section is dedicated to verifying whether this analysis is corroborated by empirical facts.

\section{Empirical Support: Evidence of an Increase in Strategic Complemen- tarities Due to Globalization}

This section provides empirical evidence supporting each step of the theoretical result established in the previous part: (1) large firms have higher and more elastic markups and, as a result, do less pass-through shocks into prices; (2) the share of output produced by large firms increases with globalization due to the self-selection of exporters; (3) consequently, the average markup elasticity -weighted by firms' share in domestic output- increases with globalization, rendering domestic prices more rigid.

\subsection{Large firms have higher markups and do less pass-through shocks into prices}

This point has been well established in the trade-literature. Berman et al. (2012) focus empirically on individual exporters' behavior facing exchange rate shocks. They show that high-productivity (also large) exporters exhibit higher markup and lower exchange rate pass-through than small firms. ${ }^{35}$ Typically, for the highest decile in terms of size, exporters increase their export price by $2.5 \%$ following a $10 \%$ depreciation of the exchange rate whereas no pricing-to-market is detected for the lowest decile, which means the pass-through is complete. Amiti et al. (2015) extend the conclusions regarding markup elasticity to a broader context (not restricted to exporters). They study the relation between firms' size and the degree of strategic complementarity, and provide empirical evidence that small firms exhibit much less strategic complementarities than large firms: "small firms [show] no strategic complementarities and a complete cost pass-through, while large

\footnotetext{
${ }^{35}$ See also Burstein and Gopinath (2013), Auer and Schoenle (2015), Amiti et al. (2014).
} 
firms [respond] to their cost shocks and competitor price changes with roughly equal elasticities of around one-half".

The aforementioned empirical findings suggest that the markup elasticity (with respect to price) is increasing in firm size. Actually, as already shown by Garetto (2014) or Auer and Schoenle (2015), a model with oligopolistic competition predicts a hump-shaped relation between markup elasticity and a firm's market share. Amiti et al. (2015) note that markup elasticity is monotonically increasing at least for market shares lower that 50\%. Specifically, in my framework, the market share threshold, after which the markup elasticity starts decreasing, is $\xi \simeq 95 \%$. Given the discrete productivity distribution I have chosen, it is never the case that one firm has such a large market share within a sector. Thus, it is reasonable to consider that the markup elasticity is increasing in firm's size.

\subsection{The share of output produced by large firms increases with globalization due to the self-selection of exporters}

As international trade costs decline, new firms start exporting. Since Bernard and Jensen (1999), we know that exporters are different from the average population of domestic firms: they are more productive and larger. Thus, when the number of exporters among domestic firms increases, the share of domestic production supplied by large firms increases. Figures 8 and 9 plot the share of U.S. employees working respectively for very large firms and for small firms. The former has dropped by $17 \%$ from 1991 to 2014 while the latter has increased by $8 \%$.

\subsection{The overall degree of real rigidity, stemming from firms'market power, increases with globalization}

The growing share of output supplied by large firms increases the average markup in the economy (weighted by firms' share in domestic production). Since high markups are also more elastic, price adjustments are dampened as shocks are getting absorbed through markup adjustments.

Melitz and Ottaviano (2008) also notice that trade liberalization might lead in the long run to less competition (in the case of a unilateral trade liberalization). Considering another form of asymmetry, Edmond et al. (2015) show that markups could in theory increase with trade liberal- 


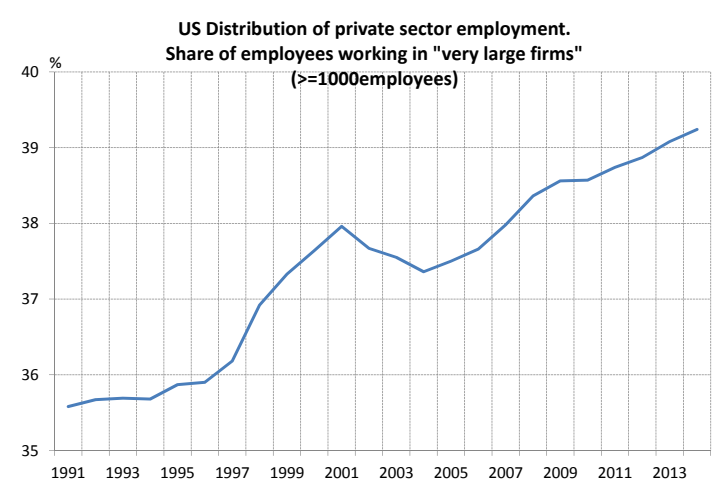

Figure 8: Share of employees working in very large firms

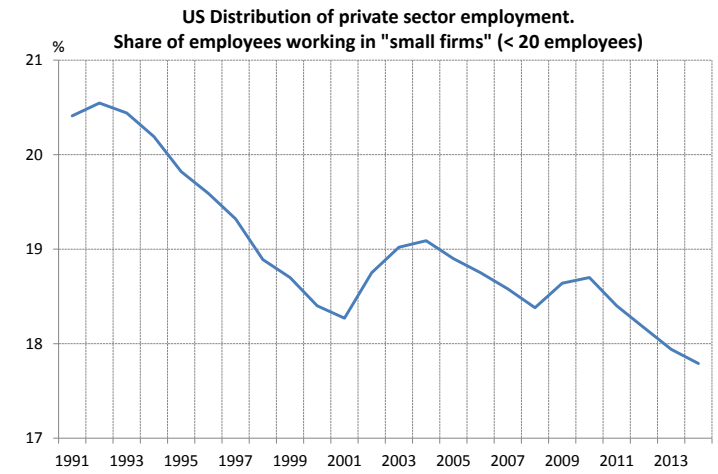

Figure 9: Share of employees working in small firms

ization when there are large cross-country differences in productivity: "Openness to trade might allow producers from one country to substantially increase their market share in the other country, thereby increasing markups". Yet, studying empirically how the distribution of markups in Taiwan changes with international trade, they find an unambiguously pro-competitive effect on Taiwanese firms' markups. Those results are not contradicting the prediction of my model though. In fact, wether the pro-competitive or the pro-concentration force dominates depends on the weight of superstar exporters in domestic production, and on how "super-high" their markups are, relative to the average population. If a country is largely open (like Taiwan) and there are sufficiently many exporters, then the model predicts that the pro-competitive force indeed dominates because exporters are not any longer very different from the average population. Focusing on seven European Union countries, Chen et al. (2009) find that the long-run effects of trade liberalization are ambiguous [compared to the short-run ones that are always pro-competitive] and "may even be anti-competitive."

Remarkably, the increase in the overall degree of market power in the domestic economy is consistent with individual firms loosing market power on their domestic market. As a matter of fact, the mechanism I describe is consistent with De Blas and Russ (2010) findings. They show that when trade costs fall, the average markup for domestic producers on their home market falls, while the average markup for exporters increases (exhibiting anticompetitive effects). Overall, they conclude that the first effect dominates and the average markup declines. To reconcile my work with 
their views, it should be understood that we consider different time horizons. I am looking at a very long time horizon (about thirty years) and I focus on the changes in the market structure -i.e. changes in the set of exporters, basically from an almost autarkic economy to an open economy with a few superstar-exporters. De Blas and Russ (2010) look at the impact of trade liberalization over a shorter term horizon. The mechanism that I describe is also in line with Arkolakis et al. (2015) who show that a fall in trade costs might increase markups of firms engaged in international trade, which leads to the conclusion that "pro-competitive effects of trade are elusive".

Last, De Loecker et al. (2016) provide empirical micro evidence that trade openness can engender markup's increase at the firm level. They show that, after an episode of trade liberalization in India, prices fell by 18pp, marginal costs declined by 31pp (thanks to cheaper imported inputs) and markups increased by 13pp. I do not model input trade and thereby I cannot capture this channel. In my model, domestic firms necessarily lose market power in the domestic market in response to trade liberalization. But incorporating input trade in the model should increase the dispersion in markups because the most productive firm will grow bigger by accessing cheap imported inputs, which actually increases its relative productivity on the domestic market. In that line, accounting for input trade would strengthen the pro-concentration force induced by globalization.

Wrapping up, the average market power basically strengthens if the concentration force is strong enough: the country is open and trade is dominated by a few superstars. ${ }^{36}$ For the United States and most large European countries, this condition seems to be documented in empirical studies as Bernard and Jensen (1999), Bernard et al. (2007), Eaton et al. (2011).

More generally, the literature on granularity demonstrates that the behavior of a few firms -at the top of the size distribution- account for a large part of the aggregate macroeconomic fluctuations. Gabaix (2011) or Carvalho and Grassi (2015) provide in their respective introductions several pieces of anecdotal evidence highlighting the key role of a few multinationals in shaping countries' output fluctuations. ${ }^{37}$ Note that, in this granular view, idiosyncratic shocks to large firms account for aggregate variables movements. In my work, the point is a bit different since the economy can

\footnotetext{
${ }^{36}$ The condition for the anti-competitive force to come up is that exporters are sufficiently different from the rest of the population (i.e. sufficiently bigger). This supposes that the country is open, so that the weight of exporters is non-negligible in the domestic output, but not too many firms export, otherwise exporters are not superstars anymore. Indeed, if a country becomes extremely open and the set of exporters enlarges up to the limit of the whole population, then new exporters are marginally less and less productive and the differential with non exporters shrinks.

${ }^{37}$ Gabaix (2011) finds that the sales of the top 50 U.S. firms are $24 \%$ of GDP, while the sales of the top 100 firms are $29 \%$ of U.S. GDP. Carvalho and Grassi (2015) show that the largest $0.02 \%$ of U.S. firms account for $20 \%$ of all employment.
} 
be hit by aggregate shocks only. But the endogenous response of large firms to a given aggregate shock is different from the one of small firms. Hence large firms' behavior matters for understanding aggregate inflation dynamics.

\section{Conclusion}

I have developed a general equilibrium setup that can rationalize the loosening of the inflation/domestic slack nexus in response to a fall in trade costs. Two forces are simultaneously playing in opposite directions in response to globalization. On the one hand, the increase in the number of goods competing on the domestic market reduces firms' market power. This decline in real rigidities renders price adjustments more responsive to marginal cost fluctuations. Thus, the pro-competitive force reinforces the link between inflation and demand pressures on domestic factors.

On the other hand, the re-allocation effect increases concentration into the largest firms -who play strategically with their markup- which subsequently reduces the responsiveness of inflation to marginal cost shocks.

At the aggregate level, if the re-allocation/concentration effect dominates the pro-competitive effect, then the Phillips curve flattens. I show that it can indeed be the case: for a parametrization of the model that replicates simple features of international trade, the sensitivity of domestic inflation to domestic marginal cost decreases.

Last, I have provided recent empirical evidence corroborating each part of this theory: (1) large firms have higher and more elastic markups and they do less pass-through shocks into prices; (2) economy has become more granular/concentrated as the share of output produced by large firms has increased with globalization -due to the self-selection of exporters; (3) consequently, the average markup and the markup elasticity may have increased with globalization, loosening the link between inflation and domestic demand pressures. 


\section{A Notations}

The notations read as follows:

\begin{tabular}{ll}
\hline Notation & refers to \\
\hline$d$ & a firm from country D serving market $\mathrm{D}$ \\
$d *$ & a firm from country D serving market $\mathrm{F}$ \\
$f *$ & a firm from country F serving market $\mathrm{F}$ \\
$f$ & a firm from country F serving market $\mathrm{D}$ \\
$N^{d} ; N^{f *}$ & the number of firms located in a representative sector of country $D$ or $F$ \\
$\frac{N^{d *}}{N^{d}} ; \frac{N^{f}}{N^{f *}}$ & the share of exporters in country $D$ and $F$ \\
\hline
\end{tabular}

\section{B Export Component of Profit for Intermediate Goods Producer}

Maximization of the export component of profits

$$
\begin{aligned}
\max _{x_{t+j}^{d *}(z)} \sum_{j=0}^{\infty} \mathbb{E}_{t}\left[Q_{t, t+j} e_{t+j}\right. & \left(P_{t+j}^{d *}(z) x_{t+j}^{d *}(z)-\tau \frac{W_{t+j}}{e_{t+j} A_{t+j} z} x_{t+j}^{d *}(z)\right. \\
& \left.\left.-\frac{\phi_{p}}{2}\left(\frac{P_{t+j}^{d *}(z)}{P_{t+j-1}^{d *}(z)}-1\right)^{2} P_{t+j}^{d *}(z) x_{t+j}^{d *}(z)-\frac{f_{X} P_{t+j}}{e_{t+j}}\right)\right]
\end{aligned}
$$

s.t.

$$
\begin{aligned}
& P_{t}^{d *}(z)=\left(\frac{x_{t}^{d *}(z)}{Y_{t}^{*}}\right)^{-\frac{1}{\theta}} P_{t}^{*} \\
& Q_{t, t+j}=\beta^{j} \frac{U^{\prime}\left(C_{t+j}\right)}{U^{\prime}\left(C_{t}\right)} \frac{P_{t}}{P_{t+j}}
\end{aligned}
$$

Optimality conditions:

$$
\frac{P_{t}^{d *}(z)}{P_{t}^{*}}=p_{t}^{d *}(z)=\operatorname{rer}_{t}^{-1} \mu_{t}^{d *}(z) \tau_{t} \frac{w_{t}}{A_{t} z}, \text { with } \operatorname{rer}_{t}=\frac{e_{t} P_{t}^{*}}{P_{t}}
$$


with

$$
\begin{aligned}
& \mu_{t}^{d *}(z)=\frac{\Theta_{t}^{d *}(z)}{\left(\Theta^{d *} t(z)-1\right)\left[1-\frac{\phi_{p}}{2}\left(\Pi_{t}^{d *}(z)-1\right)^{2}\right]+\phi_{p} \Pi_{t}^{d *}(z)\left(\Pi_{t}^{d *}(z)-1\right)-\Gamma_{t}^{d *}(z)} \\
& \Theta_{t}^{d *}(z)=\left[\frac{1}{\theta}+\left(\frac{1}{\sigma}-\frac{1}{\theta}\right)\left(\frac{P_{t}^{d *}(z)}{P_{t}^{*}(k)}\right)^{1-\theta}\right]^{-1} \\
& \Gamma_{t}^{d *}(z)=\phi_{p} \mathbb{E}\left[Q_{t, t+1}^{*} \Pi_{t+1}^{d *}(z)^{2}\left(\Pi_{t+1}^{d *}(z)-1\right) \frac{x_{t+1}^{d *}(z)}{x_{t}^{d *}(z)}\right] \\
& \Pi_{t}^{d *}(z)=\frac{P_{t}^{d *}(z)}{P_{t-1}^{d *}(z)}
\end{aligned}
$$

\section{Closing the General Equilibrium}

\section{C.1 Demand side}

The demand side is very similar to Ghironi and Melitz (2005). I assume that the economy is composed of two countries, domestic $(D)$ and foreign $(F)$. In each country, a representative household maximizes its expected intertemporal utility, $\mathbb{E}_{0} \sum_{t=0}^{\infty} \beta^{t} U\left(C_{t}, L\right)$, by choosing consumption, $C_{t}$, and assets holdings (risk-free nominal bonds), $B_{t}$. $\beta$ is a subjective discount factor. $R_{t-1}=1+r_{t-1}^{n}$ is the nominal return on bonds from $t-1$ to $t$. Domestic bonds are only traded among domestic households. The financial autarky assumption simplifies the exposition and does not alter the conclusions. ${ }^{38}$ The representative household owns firms that pay dividends $\left(D_{t}\right)$ and receives income from labor, $W_{t} L$. $L$ is in fixed supply and $W_{t}$ is the nominal wage determined competitively on the labor market. $D_{t}=N^{d} \tilde{d}_{t} P_{t}$, where $\tilde{d}_{t}$ is the average firms' dividends, $N^{d}$ is the number of firms located in country $D$ and $P_{t}$ is the consumption price index. The first order conditions for consumption and bonds choice give the usual Euler equation: $\left.U^{\prime}\left(C_{t}\right)=\beta R_{t} \mathbb{E}\left[\frac{U^{\prime}\left(C_{t+1}\right.}{\Pi_{t+1}}\right)\right]$, with $\Pi_{t+1}=\frac{P_{t+1}}{P_{t}}$.

The stochastic discount factor that shows up in firms' profit maximization programm is defined as $Q_{t, t+j}=\beta^{j} \frac{U^{\prime}\left(C_{t+j}\right)}{U^{\prime}\left(C_{t}\right)} \frac{P_{t}}{P_{t+j}}$.

The problem of the representative household in country $F$ is exactly the same, but consumption,

\footnotetext{
${ }^{38}$ This is because I have a partial equilibrium approach and I solely focus on steady state values that pin down the short-run response of inflation to domestic slack in a structural Phillips curve. Would I need to look at the impulse responses of endogenous variables to various shocks, then this simplification would be problematic. But my purpose is to assess the impact of globalization on the steady state market structure -and incidently on the slope of the structural Phillips curve. Hence I can assume financial autarky without loss of generality.
} 
dividends, bonds and prices are denoted with a superscript star. As explained in Appendix A, the number of firms located in country F and serving country $F$ market is $N^{f *}$.

\section{C.2 Monetary Policy}

The monetary authority in each country follows a standard Taylor rule to set the nominal interest rate $R_{t}$.

$$
\left.\left.\log \left(R_{t}\right)=\log (R)+\gamma_{\pi}\left(\log \left(\Pi_{t}\right)-\log (\Pi)\right)\right)+\gamma_{y}\left(\log \left(Y_{t}\right)\right)-\log (Y)\right)
$$

Anyways, since I will focus only on steady state equilibria, the choice of the rule is irrelevant for my conclusions.

\section{C.3 Aggregate Equilibrium Conditions}

The aggregate accounting equation for households budget constraint implies that total expenditure for consumption is equal to the aggregate total income from labor and dividends: $C_{t}=w_{t} L+N^{d} \tilde{d}_{t}$, with $\tilde{d}_{t}=\frac{1}{N^{d}}\left[\sum_{z_{1}^{d}}^{z_{N}} d_{t}^{d}(z)+\sum_{z_{1}^{N_{t}}}^{z} d_{t}^{d *}(z)\right]$ and $w_{t}=\frac{W_{t}}{P_{t}}$.

\section{C.3.1 Market clearing}

Bonds market, labor market and final consumption good market clear in each country.

- Bonds market: $b_{t}=\frac{B_{t}}{P_{t}}=0$,

- Labor market: $L=\int_{0}^{1}\left(\sum_{z_{1}^{d}}^{z_{N^{d}}} h_{t}^{d}(z)+\sum_{z_{1}}^{z_{t}^{d *}} \tau h_{t}^{d *}(z)\right) d k=\sum_{z_{1}}^{z_{N^{d}}} h_{t}^{d}(z)+\sum_{z_{1}}^{z_{N_{t}^{d *}}} \tau h_{t}^{d *}(z)$.

- Final consumption good market: the total amount of final good consumed (households consumption plus cost of adjusting prices and export market penetration costs) is equal to the total amount of final good produced, i.e. $Y_{t}^{\text {absorbtion }}=Y_{t}^{\text {supply }}$ with

$$
\left\{\begin{array}{l}
Y_{t}^{\text {absorbtion }}=C_{t}+P A C_{t}+N_{t}^{d *} f_{X} \\
Y_{t}^{\text {supply }}=\left[\sum_{z_{1}}^{z_{N^{d}}} x_{t}^{d}(z)^{\frac{\theta-1}{\theta}}+\sum_{z_{1}}^{N_{t}^{f}} x_{t}^{f}(z)^{\frac{\theta-1}{\theta}}\right]^{\frac{\theta}{\theta-1}}
\end{array}\right.
$$

All those equilibrium conditions hold symmetrically for the foreign country. 


\section{C.3.2 Trade Balance}

Under financial autarky, trade is balanced: $\sum_{z_{1}{ }^{d_{t}^{*}}}^{{ }^{*}} P_{t}^{d *}(z) x_{t}^{d *}(z) e_{t}=\sum_{z_{1}}^{z_{N} f_{t}} P_{t}^{f}(z) x_{t}^{f}(z)$.

\section{C.4 Equilibrium Definition}

I denote $p_{t}^{x}(z)$ the relative price of a good produced by firm $z$, expressed in unit of consumption of the destination market, e.g. $p_{t}^{d}(z)=\frac{P_{t}^{d}(z)}{P_{t}}$ on the domestic market and $p_{t}^{d *}(z)=\frac{P_{t}^{d *}(z)}{P_{t}^{*}}$ for exports.

Definition 1. An equilibrium is defined as

1. sets of aggregate quantities $\left\{C_{t}, Y_{t}, N^{d} \widetilde{d}_{t}\right\}$ and prices $\left\{R_{t}, w_{t}, \pi_{t}, r e r_{t}\right\}$, for the domestic and symmetrically for the foreign country

2. a number of exporters: $N_{t}^{d *}$ in the domestic country and $N_{t}^{f}$ in the foreign country

3. firm-level quantities $\left\{x_{t}^{d}(z), x_{t}^{d *}(z)\right\}$, relative prices $\left\{p_{t}^{d}(z), p_{t}^{d *}(z)\right\}$, price adjustments $\left\{\pi_{t}^{d}(z), \pi_{t}^{d *}(z)\right\}$, markups $\left\{\mu_{t}^{d}(z), \mu_{t}^{d *}(z)\right\}$ and price elasticity of demand $\left\{\Theta_{t}^{d}(z), \Theta_{t}^{d *}(z)\right\}$, for the domestic and symmetrically for the foreign country

such that:

- given aggregate variables, the optimality conditions are satisfied for all firms in the domestic and in the foreign country;

- given aggregate prices, representative households maximize their utility in each country

- the monetary authority in each country sets interest rates following a Taylor rule

- labor market, bonds market and final consumption good market clear in each country;

- trade is balanced across countries: $\sum_{z_{1}^{N^{d *}}}^{d_{t}^{*}} p_{t}^{d *}(z) x_{t}^{d *}(z) \operatorname{rer}_{t}=\sum_{z_{1} f_{t}}^{f_{t}} p_{t}^{f}(z) x_{t}^{f}(z)$

- the aggregate price index is consistent with individual prices: $1=\sum_{z_{1}}^{z_{N}} p_{t}^{d}(z)^{1-\theta}+\sum_{z_{1}}^{z_{N} f_{t}} p_{t}^{f}(z)^{1-\theta}$

The equilibrium equations allowing to pin down all the equilibrium variables are summarized in Table $2 .{ }^{39}$

\footnotetext{
${ }^{39}$ Note that if the aggregate accounting equation holds and the final consumption good market is balanced, then the labor market clearing conditions is necessarily satisfied. More generally if two of the three conditions hold, then the third one is redundant.
} 


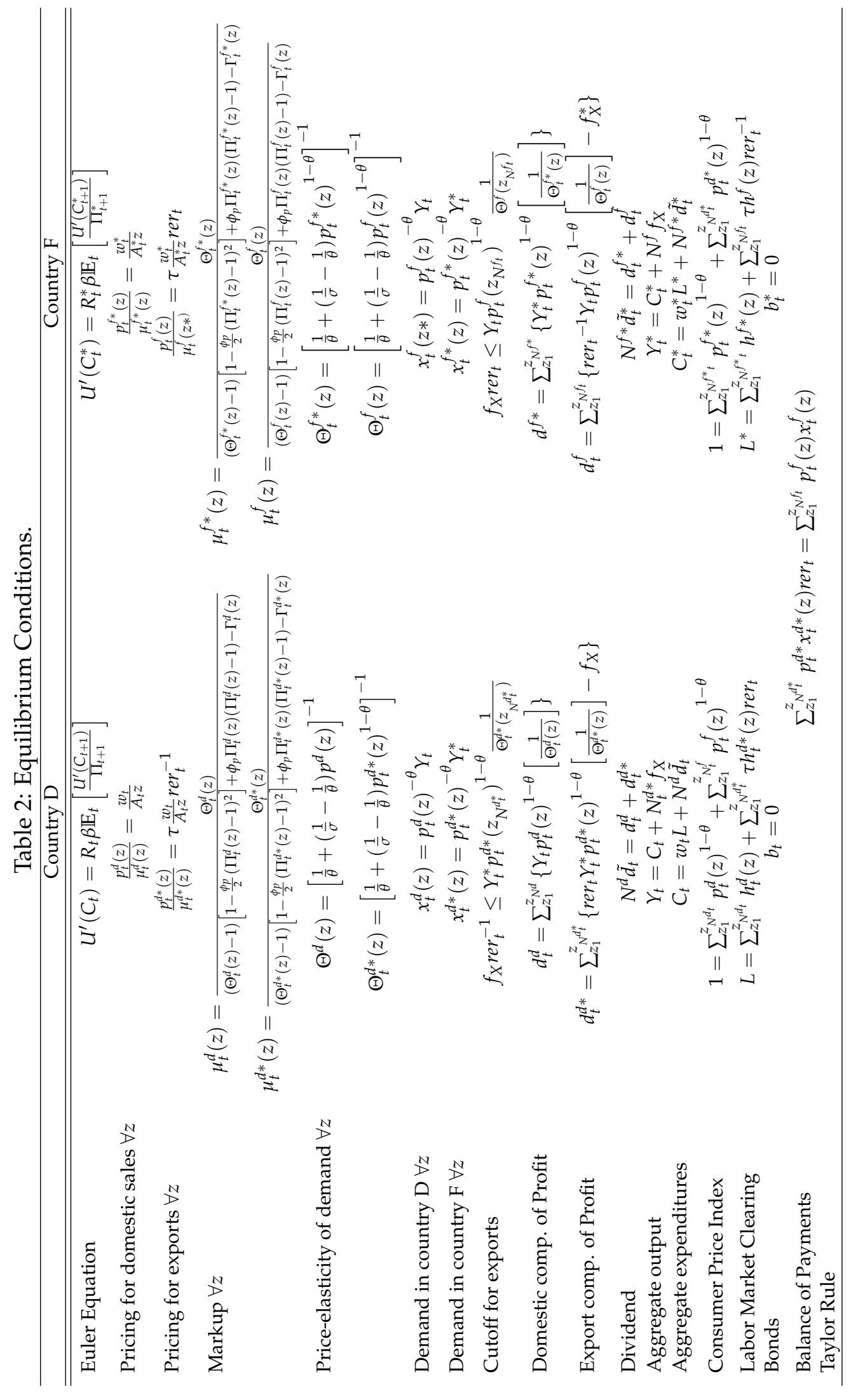




\section{Steady State}

I suppose that the two countries are symmetric. Thus the real exchange rate is 1 in steady state. Aggregate inflation and individual producer price changes are assumed equal to zero in steady state. Importantly, throughout the paper sectors are symmetric. Thus, in equilibrium, $\forall k, P_{t}(k)=$ $P_{t}, Y_{t}(k)=Y_{t}$

\section{D.1 Optimality and Equilibrium Conditions in steady State}

All the steady state equilibrium conditions are summarized in Table 3.

\section{D.2 Solving for the steady state}

\section{D.2.1 Intermediate step: characterizing the relative price, $p^{x}$, as a function of the real marginal cost}

$p^{x}(z)$ is a general notation for the relative price of an intermediate good produced by a firm with productivity $z$. It may be either $p^{d}(z)=\frac{P^{d}(z)}{P}$ or $p^{d *}(z)=\frac{P^{d *}(z)}{P^{*}}$, depending on the destination market. I define the effective real marginal cost as $s_{e}^{r}=\frac{w}{A z} \tau$, with $\tau=1$ for goods sold domestically and $\tau \geq 1$ for goods that are exported. Note that $P=P^{*}$ and $r e r=1$ in steady state.

Lemma 1. In zero-inflation steady state equilibrium, with symmetric sectors, the optimal pricing rule defined in equations 4 and 12 can be re-written in terms of relative price as

$$
p^{x}=\frac{\left[\frac{1}{\theta}+\left(\frac{1}{\sigma}-\frac{1}{\theta}\right) p^{x 1-\theta}\right]^{-1}}{\left[\frac{1}{\theta}+\left(\frac{1}{\sigma}-\frac{1}{\theta}\right) p^{x 1-\theta}\right]^{-1}-1} s_{e}^{r}
$$

Equation 14 implicitly defines the optimal relative price, $p^{x}$, as a monotone increasing convex function in the effective real marginal cost, $s_{e}^{r}$.

Proof. See Appendix G. Key is the symmetry across sectors. Thus, in equilibrium, $\forall k: P(k)=$ $P$. Consequently, I can divide both sides of equations 4 or 12 by $P(k)=P$ and the non-linear relationship between $p^{x}$ and $s_{e}^{r}$ arises.

Corollary 3. In steady state equilibrium, the optimal relative price $p^{x}$ is a decreasing convex function in the relative productivity $z$. 


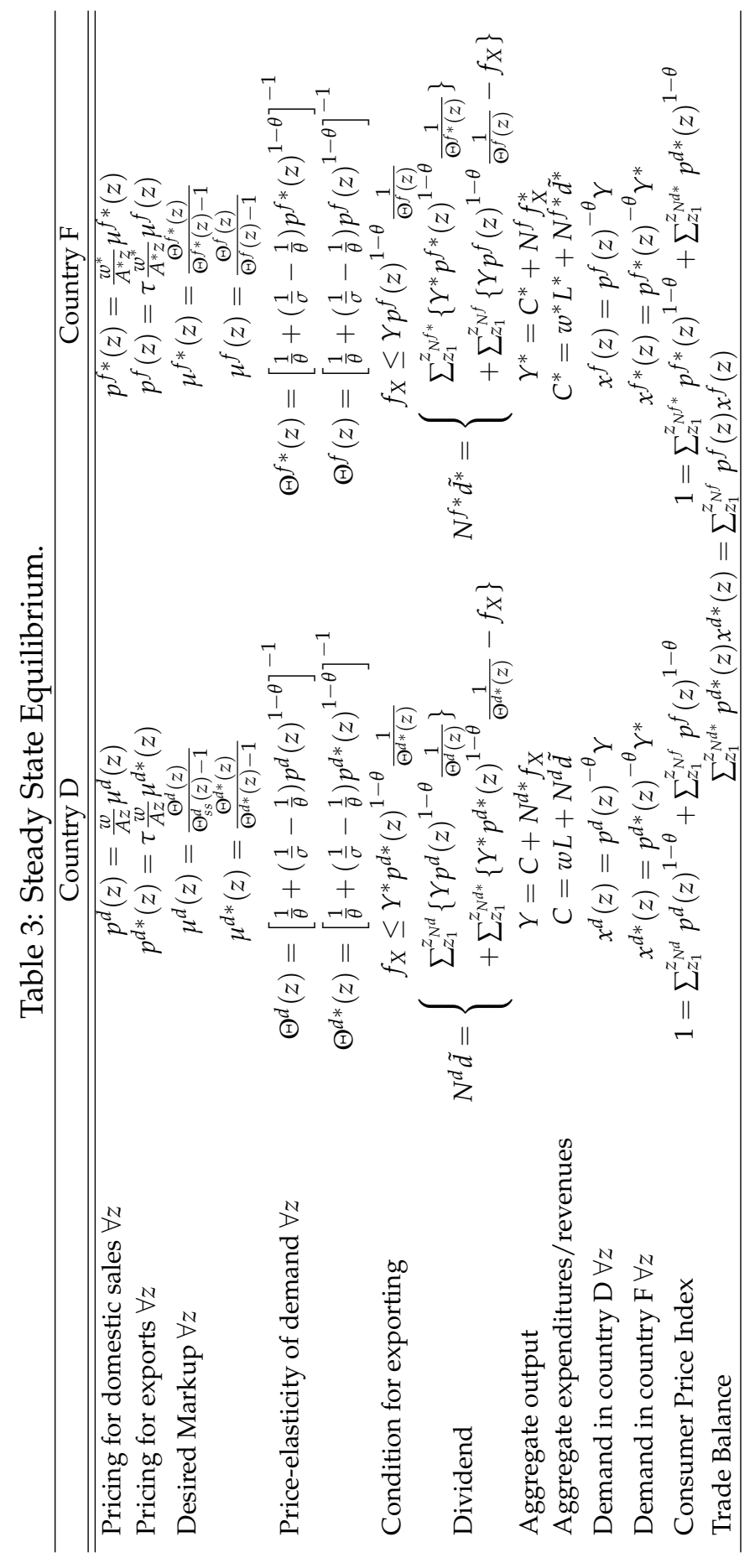


Proof. The corollary follows directly from the previous Lemma because $s_{e}^{r}=\frac{w}{A z} \tau$ (with $\tau=1$ for serving the domestic market). Since $\frac{\partial p^{x}}{\partial s_{e}^{r}} \geq 0$, then $\frac{\partial p^{x}}{\partial z}=\frac{\partial p^{x}}{\partial s_{e}^{r}} \frac{\partial s_{e}^{r}}{\partial z}(z) \leq 0$.

Figure 10 illustrates the bijection in equilibrium between $s_{e}^{r}$ and $p^{x}$ and between $z$ and $p^{x}$, for a given equilibrium real wage $w$ and a given $A$.
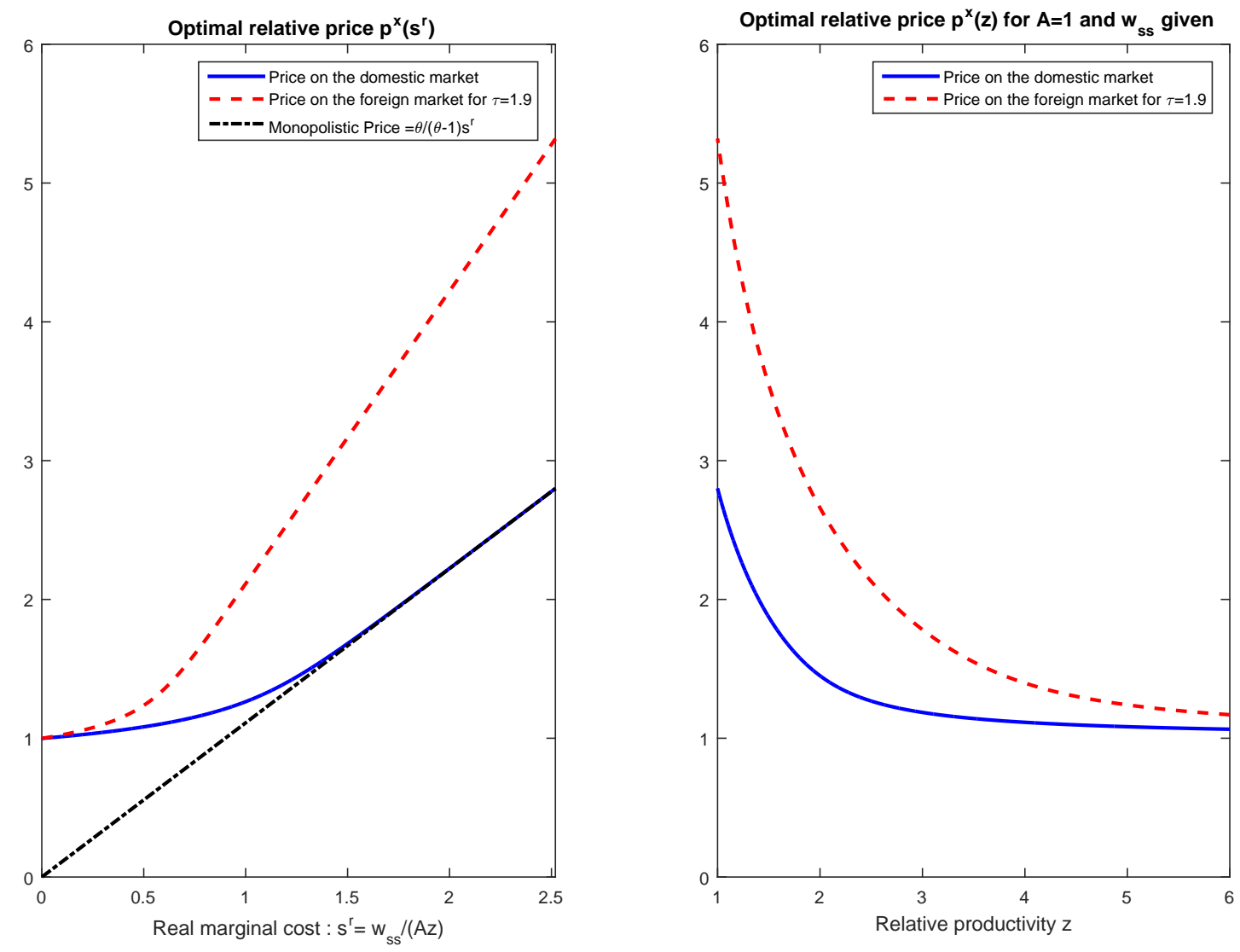

Figure 10: Optimal Relative Price in Equilibrium

\section{D.2.2 Solution Algorithm}

Recall that in a symmetric-country equilibrium, $Y=Y^{*}, w=w^{*}, p^{d *}=p^{f}$ and $N^{d *}=N^{f}$. I solve for the steady state following a sequential entry procedure, in the spirit of Atkeson and Burstein (2008). I start with the guess that only the most productive firm in each sector is exporting: $N^{d *}=N^{f}=1$. I initiate the loop by setting the number of iteration equal to one: $\sharp_{\text {iter }}=1$. 
1. Step 1: Solve for the steady state real wage using Corollary 3 , and the price index equation. By Corollary 3, all prices can be expressed as a function of $z$ for a given real wage $w$, denoted $p^{x}(z \mid w)$. Thus the equilibrium real wage, $w$, is solution of the following equation:

$$
1=\sum_{z_{1}}^{z_{N^{d}}} p^{d^{1-\theta}}(z \mid w)+\sum_{z_{1}}^{z_{N} f} p^{f^{1-\theta}}(z \mid w)
$$

Given the guessed number of exporters, solving equation 15 gives the equilibrium wage. By Lemma 1, all the relative prices set by firms on each market can be recovered.

2. Step 2: Having $w$ and all the relative prices of active firms (on domestic and foreign markets) , I use the aggregate output and aggregate accounting equations (see Table 3 ) to solve for $Y$.

$$
Y-N^{d *} f_{X}=C=w L+N^{d} \tilde{d}
$$

Thus $Y$ can be written as a function of the guessed number of exporters $\left(N^{d *}\right)$, the associated equilibrium real wage $(w)$, and the parameters.

$$
Y=\frac{N^{d *} f_{X}+w L}{\left(1-\sum_{z_{1}}^{z_{N^{d}}}\left\{p^{d}(z \mid w)^{1-\theta}\left[\frac{1}{\theta}+\left(\frac{1}{\sigma}-\frac{1}{\theta}\right) p^{d}(z \mid w)^{1-\theta}\right]\right\}-\sum_{z_{1}}^{z^{f}}\left\{p^{f}(z \mid w)^{1-\theta}\left[\frac{1}{\theta}+\left(\frac{1}{\sigma}-\frac{1}{\theta}\right) p^{f}(z \mid w)^{1-\theta}\right]\right\}\right)}
$$

3. Step 3: Given the pair $\{w, Y\}$ and the relative prices of active firms implied by the set of exporters, I check wether the cutoff exporter (with productivity $z_{N^{d *}}$ ) indeed makes positive profit.

(a) if $Y^{*} p^{d *}(z \mid w)^{1-\theta}\left[\frac{1}{\theta}+\left(\frac{1}{\sigma}-\frac{1}{\theta}\right) p^{d *}(z \mid w)^{1-\theta}\right] \geq f_{X}$ for $z=z_{N^{d *}}$ : then I start again the procedure from step 1 , with $\sharp_{\text {iter }}=\sharp_{\text {iter }}+1$, making the next most productive firm become the cutoff exporter.

(b) if profit is negative: then the loop stops. An equilibrium is reached, comprising $N_{s s}^{d *}=$ $\sharp_{\text {iter }}-1$ exporters.

Note that from now on, I denote the steady state equilibrium values with a subscript ${ }_{s s}$. Given the equilibrium set of exporters $N_{s s}^{d *}$, I get the associated equilibrium real wage $w_{s s}$, output $Y_{s s}$, and all relative prices of active firms on each market, following steps 1 and 2. And eventually I can recover all the remaining endogenous variables using Table 3. 
I am now able to compute the steady state for different values of iceberg trade costs, $\tau$.

\section{E Openness to Trade}

$$
\omega_{s S}=\frac{\sum_{z_{1}^{d}}^{z^{d}} P^{d}{ }_{S S}(z) x_{s S}^{d}(z)}{P_{S S} Y_{S S}}=\sum_{z_{1}}^{z_{N^{d}}} p_{s S}^{d}(z)^{1-\theta}=N^{d} \widetilde{\widetilde{\xi}_{s S}^{d}}
$$

Besides, $1-\omega_{s S}^{*}=1-\omega_{s S}$ because by symmetry, in steady state: $N_{s S}^{f}=N_{S S}^{d *}$ and $p_{s s}^{f}(z)=p_{s s}^{d *}(z)$.

$$
1-\omega_{s s}=\frac{\sum_{z_{1}}^{z_{s s}^{f}} P^{f}{ }_{s s}(z) x_{s s}^{f}(z)}{P_{S S} Y_{s s}}=\sum_{z_{1}}^{z_{s s}^{f}} p_{s s}^{f}(z)^{1-\theta}=N_{s s}^{f} \tilde{\xi}_{s s}^{f}
$$

\section{F Discrete Productivity Distribution}

The discrete distribution is constructed to mimic an underlying continuous Pareto distribution similar to Ghironi and Melitz (2005) - but bounded on the right. Suppose that $Z$ is a random variable drawn from the underlying truncated Pareto law with scale parameters $\zeta_{\min }, \zeta_{\max }$ and shape parameter $k$. The Probability Density Function is $g(\zeta)=\frac{k \zeta_{\min }^{k}}{\zeta^{k+1}} \frac{1}{1-\left(\frac{\zeta_{\min }}{\zeta_{\max }}\right)^{k}}, \forall \zeta \in\left[\zeta_{\min }, \zeta_{\max }\right]$, and $g(\zeta)=0$ otherwise. Its Cumulative Density Function is $G(\bar{\zeta})=\mathbb{P}(\zeta \leq \bar{\zeta})=\frac{1-\left(\frac{\zeta_{\min }}{\zeta}\right)^{k}}{1-\left(\frac{\zeta_{\min }}{\zeta_{\max }}\right)^{k}}$.

Fix the number of firms per sector, $N^{d}=N^{f *}=N$ (it is a parameter of the model). The goal is to divide the support into $N$ bins such that the probability for the original random variable $-\zeta$ - to lie in each bin is $1 / N$. Denote $\zeta_{i}$ and $\zeta_{i+1}$ the values of the nodes that delimit the $i^{\text {th }}$ most productive bin, $B_{i}$. By construction, $\zeta_{1}=\zeta_{\max }, \zeta_{N+1}=\zeta_{\min }$ and $\zeta_{i}$ is such that $\forall i \in\{1, . ., N\}: \mathbb{P}\left(\zeta \leq \zeta_{i}\right)=\frac{N-i+1}{N}$. Last, I compute the average productivity in bin $B_{i}$ as $z_{i}=\left[\int_{\zeta_{i+1}}^{\zeta_{i}} \zeta^{\theta-1} g(\zeta) d \zeta\right]^{\frac{1}{\theta-1}}, \forall i \in\{1, . ., N\}$. Eventually, the discrete distribution of firms' productivity in each sector is $\left\{z_{1}, z_{2}, \ldots, z_{N}\right\}$.

Note that if the underlying continuous Pareto law were not initially bounded, I could still follow the same methodology, but I would have to impose the condition that $-k+\theta-1<0$ in order to ensure that the productivity in the most productive bin is finite $\left(z_{1}=\left[\int_{\zeta_{2}}^{\zeta_{1}} \zeta^{\theta-1} g(\zeta) d \zeta\right]^{\frac{1}{\theta-1}}<\infty\right.$ for $\zeta_{1}=\infty$ ). Since $\theta$ is high within sector, that gives a high parameter shape $k$ for the productivity distribution, which is not in line with the literature and empirical findings. 


\section{G Optimal Relative Price as an Increasing Convex Function in the Real Marginal Cost}

In the monopolistic case there is a linear relationship between the optimal relative price and the real marginal cost, $p^{x}=\mu s_{e}^{r}$. In the oligopolistic case, equations (4) or (12) relate the optimal relative price to firm's real marginal cost in a non linear way:

$$
p^{x}=\frac{\Theta\left(p^{x}\right)}{\Theta\left(p^{x}\right)-1} s_{e}^{r}=\frac{\left[\frac{1}{\theta}-\left(\frac{1}{\theta}-\frac{1}{\sigma}\right) p^{x 1-\theta}\right]^{-1}}{\left[\frac{1}{\theta}-\left(\frac{1}{\theta}-\frac{1}{\sigma}\right) p^{x 1-\theta}\right]^{-1}-1} s_{e}^{r}
$$

I want to check that, for any given real marginal cost $s_{e}^{r}$, a firm can choose one and only one optimal relative price $p^{x}$. To that end I study $s_{e}^{r}$ as a function of $p^{x}$ and show that it is a bijection: $s_{e}^{r}$ is a monotonic increasing concave function in the relative price $p^{x}$ on $[1,+\infty]$. Thus the inverse function exists, and $p^{x}$ is strictly increasing and convex in $s_{e}^{r}$.

STEP 1: I show that $\frac{\partial s_{e}^{r}}{\partial p^{x}} \geq 0$

$$
\begin{aligned}
& \frac{\partial s_{e}^{r}}{\partial p^{x}}=\frac{\left(p^{x}\right)^{-\theta}\left(p^{x}(\theta-2)(\theta-\sigma)+\left(p^{x}\right)^{\theta}(\theta-1) \sigma\right)}{\theta \sigma} \\
\Rightarrow & \forall \theta \geq 2, \forall p^{x} \geq 1: \frac{\partial s_{e}^{r}}{\partial p^{x}} \geq 0
\end{aligned}
$$

STEP 2: I show that $\frac{\partial^{2} s_{e}^{r}}{\partial p^{x}} \leq 0$

$$
\begin{aligned}
& \frac{\partial^{2} s_{e}^{r}}{\partial p^{x 2}}=-\frac{\left(\left(p^{x}\right)^{-\theta}(\theta-2)(\theta-1)(\theta-\sigma)\right.}{\theta \sigma} \\
\Rightarrow & \forall \theta \geq 2, \forall p^{x} \geq 1: \frac{\partial^{2} s_{e}^{r}}{\partial p^{x 2}} \leq 0
\end{aligned}
$$

Hence $s_{e}^{r}$ is strictly increasing and convex in $p^{x}$.

STEP 3:

If $s_{e}^{r}$ is a monotonic increasing and concave function in $p^{x}$, then there exists a reciprocal function, $p^{x}($.$) , that is monotonically increasing and convex in s_{e}^{r}$. 
Last, noting that $s_{e}^{r}=s^{r} \tau$ with $s^{r}=\frac{w}{A z}$, the equilibrium optimal relative prices charged on the domestic and on the export markets can be computed as a function of $s^{r}$. Figure $\mathrm{G}$ is an illustrative example.

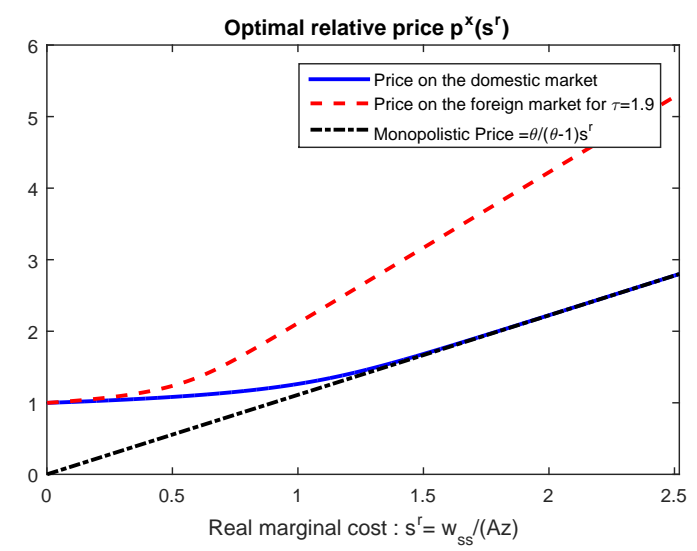




\section{References}

Alessandria, George and Horag Choi, "Do falling iceberg costs explain recent U.S. export growth?," Journal of International Economics, 2014, 94 (2), 311-325.

Amiti, Mary, Oleg Itskhoki, and Jozef Konings, "Importers, Exporters, and Exchange Rate Disconnect," American Economic Review, July 2014, 104 (7), 1942-78.

_ , _ , and _ , "International Shocks and Domestic Prices: How Large Are Strategic Complementarities?," Technical Report 2015.

Anderson, James E. and Eric van Wincoop, "Trade Costs," Journal of Economic Literature, September 2004, 42 (3), 691-751.

Arkolakis, Costas, Arnaud Costinot, Dave Donaldson, and Andrs Rodrguez-Clare, "The Elusive Pro-Competitive Effects of Trade," NBER Working Papers 21370, National Bureau of Economic Research, Inc July 2015.

Atkeson, Andrew and Ariel Burstein, "Pricing-to-Market, Trade Costs, and International Relative Prices," American Economic Review, December 2008, 98 (5), 1998-2031.

Auer, Raphael and Raphael Schoenle, "Market Structure and Exchange Rate Pass-Through," CEPR Discussion Papers, C.E.P.R. Discussion Papers May 2015.

Ball, Laurence and David Romer, "Real Rigidities and the Non-Neutrality of Money," Review of Economic Studies, 1990, 57 (2), 183-203.

- and Sandeep Mazumder, "Inflation Dynamics and the Great Recession," Brookings Papers on Economic Activity, 2011, 42 (1 (Spring), 337-405.

Benigno, Pierpaolo and Ester Faia, "Globalization, Pass-Through and Inflation Dynamic," NBER Working Papers 15842, National Bureau of Economic Research, Inc March 2010.

Bergin, Paul R. and Giancarlo Corsetti, "International Competitiveness and Monetary Policy: Strategic Policy and Coordination with a Production Relocation Externality," NBER Working Papers 19356, National Bureau of Economic Research, Inc August 2013.

Berman, Nicolas, Philippe Martin, and Thierry Mayer, "How do Different Exporters React to Exchange Rate Changes?," The Quarterly Journal of Economics, 2012, 127 (1), 437-492. 
Bernanke, Ben S., “Monetary policy under uncertainty,” Technical Report 2007.

Bernard, Andrew B. and Bradford J. Jensen, “Exceptional exporter performance: cause, effect, or both?," Journal of International Economics, February 1999, 47 (1), 1-25.

_ , J. Bradford Jensen, Stephen J. Redding, and Peter K. Schott, "Firms in International Trade," Journal of Economic Perspectives, Summer 2007, 21 (3), 105-130.

Bilbiie, Florin O., Fabio Ghironi, and Marc J. Melitz, “Endogenous Entry, Product Variety, and Business Cycles," Journal of Political Economy, 2012, 120 (2), $304-345$.

_ , Ippei Fujiwara, and Fabio Ghironi, "Optimal monetary policy with endogenous entry and product variety," Journal of Monetary Economics, 2014, 64 (C), 1-20.

Blanchard, Olivier, Eugenio Cerutti, and Lawrence H. Summers, "Inflation and Activity: Two Explorations and Their Monetary Policy Implications," Working Paper Series WP15-19, Peterson Institute for International Economics November 2015.

Borio, Claudio E. V. and Andrew Filardo, "Globalisation and inflation: New cross-country evidence on the global determinants of domestic inflation," BIS Working Papers 227, Bank for International Settlements May 2007.

Broda, Christian and David E. Weinstein, "Globalization and the Gains from Variety," The Quarterly Journal of Economics, May 2006, 121 (2), 541-585.

Burstein, Ariel and Gita Gopinath, "International Prices and Exchange Rates," NBER Working Papers 18829, National Bureau of Economic Research, Inc February 2013.

Carvalho, Vasco M and Basile Grassi, "Large Firm Dynamics and the Business Cycle," CEPR Discussion Papers 10587, C.E.P.R. Discussion Papers May 2015.

Cecioni, Martina, "Firm entry, competitive pressures and the US inflation dynamics," Temi di discussione (Economic working papers) 773, Bank of Italy, Economic Research and International Relations Area September 2010.

Chaney, Thomas, "Distorted Gravity: The Intensive and Extensive Margins of International Trade," American Economic Review, September 2008, 98 (4), 1707-21.

Chen, Natalie, Jean Imbs, and Andrew Scott, "The dynamics of trade and competition," Journal of International Economics, February 2009, 77 (1), 50-62. 
Coibion, Olivier and Yuriy Gorodnichenko, "Is the Phillips Curve Alive and Well after All? Inflation Expectations and the Missing Disinflation," American Economic Journal: Macroeconomics, January 2015, 7 (1), 197-232.

De Blas, Beatriz and Katheryn Russ, "Understanding Markups in the Open Economy under Bertrand Competition," NBER Working Papers 16587, National Bureau of Economic Research, Inc December 2010.

De Loecker, Jan, Pinelopi K. Goldberg, Amit K. Khandelwal, and Nina Pavcnik, "Prices, Markups, and Trade Reform," Econometrica, 03 2016, 84, 445-510.

Di Giovanni, Julian and Andrei A. Levchenko, "Country Size, International Trade, and Aggregate Fluctuations in Granular Economies," Journal of Political Economy, 2012, 120 (6), 1083 - 1132.

Dornbusch, Rudiger, “Exchange Rates and Prices," American Economic Review, March 1987, 77 (1), 93-106.

Eaton, Jonathan, Samuel Kortum, and Francis Kramarz, "An Anatomy of International Trade: Evidence From French Firms," Econometrica, 09 2011, 79 (5), 1453-1498.

Edmond, Chris, Virgiliu Midrigan, and Daniel Yi Xu, "Competition, Markups, and the Gains from International Trade," American Economic Review, October 2015, 105 (10), 3183-3221.

Etro, Federico and Andrea Colciago, "Endogenous Market Structures and the Business Cycle," Economic Journal, December 2010, 120 (549), 1201-1233.

- and Lorenza Rossi, "New-Keynesian Phillips curve with Bertrand competition and endogenous entry," Journal of Economic Dynamics and Control, 2015, 51 (C), 318-340.

Faia, Ester, "Oligopolistic competition and optimal monetary policy," Journal of Economic Dynamics and Control, 2012, 36 (11), 1760-1774.

Fratto, Chiara and Harald Uhlig, "Accounting for Post-Crisis Inflation and Employment: A Retro Analysis," NBER Working Papers 20707, National Bureau of Economic Research, Inc November 2014.

Gabaix, Xavier, "The Granular Origins of Aggregate Fluctuations," Econometrica, 05 2011, 79 (3), 733-772. 
Gali, Jordi and Mark Gertler, "Inflation dynamics: A structural econometric analysis," Journal of Monetary Economics, October 1999, 44 (2), 195-222.

- and Tommaso Monacelli, "Optimal monetary and fiscal policy in a currency union," Journal of International Economics, September 2008, 76 (1), 116-132.

Garetto, Stefania, "Firms' Heterogeneity and Incomplete Pass-Through," Boston University - Department of Economics - Working Papers Series WP2014-006, Boston University - Department of Economics March 2014.

Ghironi, Fabio and Marc J. Melitz, “International Trade and Macroeconomic Dynamics with Heterogeneous Firms," The Quarterly Journal of Economics, August 2005, 120 (3), 865-915.

Gopinath, Gita, Oleg Itskhoki, and Brent Neiman, "Trade Prices and the Global Trade Collapse of 200809," IMF Economic Review, September 2012, 60 (3), 303-328.

Gordon, Robert J., "The Phillips Curve is Alive and Well: Inflation and the NAIRU During the Slow Recovery," NBER Working Papers 19390, National Bureau of Economic Research, Inc August 2013.

Guerrieri, Luca, Christopher Gust, and J. David Lopez-Salido, "International Competition and Inflation: A New Keynesian Perspective," American Economic Journal: Macroeconomics, October 2010, 2 (4), 247-80.

Imbs, Jean, Eric Jondeau, and Florian Pelgrin, "Sectoral Phillips curves and the aggregate Phillips curve," Journal of Monetary Economics, 2011, 58 (4), 328-344.

International Monetary Fund, “The dog that didn't bark: Has Inflation been Muzzled or was it just Sleeping?," October 2013, Chapter III.

Jaimovich, Nir and Max Floetotto, "Firm dynamics, markup variations, and the business cycle," Journal of Monetary Economics, October 2008, 55 (7), 1238-1252.

Kohn, Donald, "The Effects of Globalization on Inflation and Their Implications for Monetary Policy," Speech, Remarks at the Federal Reserve Bank of Bostons 51st Economic Conference June 2006.

Krugman, Paul, "Pricing to Market when the Exchange Rate Changes," in S. Arndt and J. Richardson, eds., Real Financial Linkages among Open Economies, Cambridge: MIT Press, 1987, pp. 49-70. 
Leith, Campbell and Jim Malley, "A Sectoral Analysis of Price-Setting Behavior in U.S. Manufacturing Industries," The Review of Economics and Statistics, May 2007, 89 (2), 335-342.

Lewis, Vivien and Céline Poilly, "Firm entry, markups and the monetary transmission mechanism," Journal of Monetary Economics, 2012, 59 (7), 670-685.

Matheson, Troy and Emil Stavrev, "The Great Recession and the Inflation Puzzle," IMF Working Papers 13/124, International Monetary Fund May 2013.

Melitz, Marc J., "The Impact of Trade on Intra-Industry Reallocations and Aggregate Industry Productivity," Econometrica, November 2003, 71 (6), 1695-1725.

- and Gianmarco I. P. Ottaviano, "Market Size, Trade, and Productivity," Review of Economic Studies, 2008, 75 (1), 295-316.

Peach, Richard, Robert Rich, and Anna Cororaton, "How does slack influence inflation?," Current Issues in Economics and Finance, 2011, 17 (June).

Rotemberg, Julio J, "Sticky Prices in the United States," Journal of Political Economy, December 1982,90 (6), 1187-1211.

Rotemberg, Julio J. and Michael Woodford, "Oligopolistic Pricing and the Effects of Aggregate Demand on Economic Activity," NBER Working Papers 3206, National Bureau of Economic Research, Inc December 1989.

Sbordone, Argia M., "Globalization and Inflation Dynamics: The Impact of Increased Competition," in "International Dimensions of Monetary Policy" NBER Chapters, National Bureau of Economic Research, Inc, 2010, pp. 547-579.

Woodford, Michael, Interest and Prices: Foundations of a Theory of Monetary Policy, Princeton University Press, 2003. 